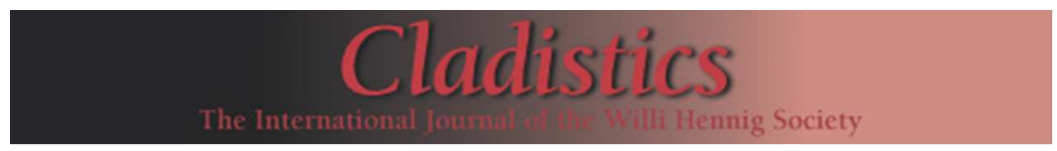

\title{
A comprehensive phylogeny of extinct and extant Rhizomyinae (Rodentia): evidence for multiple intercontinental dispersals
}

\begin{tabular}{|r|l|}
\hline Journal: & Cladistics \\
\hline Manuscript ID: & CLA-12-05-0553.R2 \\
\hline Manuscript Type: & Article \\
\hline Date Submitted by the Author: & n/a \\
\hline Complete List of Authors: & $\begin{array}{l}\text { López-Antoñanzas, Raquel; Museo Nacional de Ciencias Naturales-CSIC, } \\
\text { Paleobiology } \\
\text { Flynn, Lawrence; Harvard University, Peabody Museum } \\
\text { Knoll, Fabien; Museo Nacional de Ciencias Naturales-CSIC, Paleobiology }\end{array}$ \\
\hline Keywords: & $\begin{array}{l}\text { Paleontology, Phylogeny, Systematics, Taxonomy, Dispersal < } \\
\text { Biogeography < Applications }\end{array}$ \\
\hline
\end{tabular}

SCHOLARONE ${ }^{m}$

Manuscripts 


\begin{abstract}
The subfamily Rhizomyinae is known from the Late Oligocene up to the present. Today, this group comprises six species, which live in southern Asia and eastern Africa. Despite the current moderate diversity of the rhizomyines, they had a greater diversification and wider distribution in the past from Asia, their land of origin, to Africa where they entered during the Early Miocene. So far 33 fossil species can be referred to this group. A cladistic analysis involving fossil and living species has been carried out. Prokanisamys spp. turned out to be the most basal taxa of the ingroup. This analysis calls the monophyly of several genera into question and allows proposing a phylogenetic definition of the tribes Tachyoryctini and Rhizomyini. It also provides information about the origin of the African rhizomyines and allows inferring multiple dispersal phenomena from Asia to Africa in Early and Late Miocene times.
\end{abstract}

Keywords: Mammalia; Systematics; Cladistics; Cenozoic; Eurasia; Africa 


\section{Table of contents}

Introduction

Material and methods

Systematics

Genus Rhizomys Gray, 1831

Rhizomys sinensis Gray, 1831

Rhizomys sumatrensis (Raffles, 1821).

Rhizomys pruinosus Blyth, 1851.

Rhizomys (Brachyrhizomys) shansius (Teilhard de Chardin, 1942).

Rhizomys (Brachyrhizomys) shajius Flynn, 1993.

Genus Cannomys Thomas, 1915a.

Cannomys badius (Hodgson, 1841).

Genus Tachyoryctes (Rüppell, 1836).

Tachyoryctes splendens Rüppell, 1836.

Tachyoryctes macrocephalus (Rüppell, 1842).

Tachyoryctes pliocaenicus Sabatier, 1978.

Tachyoryctes konjiti Sabatier, 1982.

Tachyoryctes makooka Wesselman, Black et Asnake, 2009.

Genus Anepsirhizomys Flynn, 1982a.

Anepsirhizomys opdykei Flynn, 1982a.

Anepsirhizomys pinjoricus (Hinton, 1933).

Genus Miorhizomys Flynn, 2009.

Miorhizomys nagrii (Hinton, 1933).

Miorhizomys micrus (Flynn, 1982a).

Miorhizomys blacki (Flynn, 1982a). 
1

2

3

4

5

6

7

8

9

10

11

12

13

14

15

16

17

18

19

20

21

22

23

24

25

26

27

28

29

30

31

32

33

34

35

36

37

38

39

40

41

42

43

44

45

46

47

48

49

50

51

52

53

54

55

56

57

58

59

60

Miorhizomys pilgrimi (Hinton, 1933).

Miorhizomys harii (Prasad, 1968).

Miorhizomys tetracharax (Flynn, 1982a).

Miorhizomys choristos (Flynn, 1982a).

Genus Eicooryctes Flynn, 1982.

Eicooryctes kaulialensis Flynn, 1982.

Genus Protachyoryctes Hinton, 1933.

Protachyoryctes tatroti Hinton, 1933.

Genus Rhizomyides Bohlin, 1946.

Rhizomyides sivalensis (Lydekker, 1884).

Rhizomyides carbonnelli (Brandy, 1979).

Rhizomyides platytomeus Flynn, Heintz, Sen et Brunet, 1983.

Rhizomyides mirzadi (Lang et Lavocat, 1968).

Rhizomyides punjabiensis (Colbert, 1933).

Rhizomyides lydekkeri (Hinton, 1933) and Rhizomyides saketiensis (Gupta, Verma et Tewari, 1978).

Genus Kanisamys Wood, 1937.

Kanisamys indicus Wood, 1937.

Kanisamys sivalensis Wood, 1937.

Kanisamys nagrii Prasad, 1968.

Kanisamys potwarensis Flynn, 1982a.

Genus Nakalimys Flynn et Sabatier, 1984.

Nakalimys lavocati Flynn et Sabatier, 1984.

Genus Pronakalimys Tong et Jaeger, 1993. 
Pronakalimys andrewsi Tong et Jaeger, 1993.

Genus Prokanisamys de Bruijn, Hussain et Leinders, 1981.

Prokanisamys arifi de Bruijn, Hussain et Leinders, 1981.

Prokanisamys kowalskii (Lindsay, 1996).

Prokanisamys benjavuni (Mein et Ginsburg, 1985).

Prokanisamys major Wessels et de Bruijn, 2001.

Prokanisamys sp. Wessels, Fejfar, Peláez-Campomanes et de Bruijn, 2003.

Phylogenetic analysis

Previous work

New analysis

Discussion

Prokanisamys

The African Pronakalimys and Nakalimys

Kanisamys

Protachyoryctes

Rhizomyides

“Rhizomyides" mirzadi and "R".punjabiensis

Miorhizomys

The crown group

Tribe Tachyoryctini.

Tribe Rhizomyini.

\section{Conclusion}

Acknowledgements

\section{References}


López-Antoñanzas, R. et al. 1

\section{A comprehensive phylogeny of extinct and extant Rhizomyinae (Rodentia): evidence for multiple intercontinental dispersals}

Raquel López-Antoñanzas ${ }^{1}$, Lawrence J. Flynn ${ }^{2}$ and Fabien Knoll ${ }^{1}$

${ }^{1}$ Departamento de Paleobiología, Museo Nacional de Ciencias Naturales-CSIC, c/ José Gutiérrez Abascal 2, Madrid 28006, Spain.

${ }^{2}$ Peabody Museum of Archaeology and Ethnology, Harvard University, Cambridge, MA 02138. E-mails (RLA): ralopan@mncn.csic.es; (LJF): ljflynn@fas.harvard.edu, (FK): knoll@mncn.csic.es Running title

Cladistics 


\section{Introduction}

Living Rhizomyinae are fossorial muroid rodents from southern Asia and eastern Africa (Fig. 1) that belong to the family Spalacidae (Jansa and Weksler, 2004; Gogolevskaya et al., 2010). Despite their seceretive way of life, they are important to the people who live in the same zones because, like other rodents (e.g., the cane rat Thryonomys; López-Antoñanzas et al., 2004), they are agricultural pests, but also can be a source of protein.

The living Asian forms (bamboo rats) include Rhizomys (a trispecific genus) and Cannomys (a monospecific genus). There is a single living African genus Tachyoryctes, the mole rat, which includes 2 extant species, although that diversity may be greatly underestimated (Musser and Carleton, 2005). No fossil of Cannomys has been found to date. However, the Asian Rhizomys (Brachyrhizomys) and the African Tachyoryctes are known since Late Miocene time. Although the rhizomyines are today moderately diversified, this subfamily, which is known from Late Oligocene times, has had a | flourishing history as reflected by the finding discovery of over 30 fossil species distributed in 11 genera (Pronakalimys, Nakalimys, Prokanisamys, Kanisamys, Rhizomyides, Protachyoryctes, Tachyoryctes, Eicooryctes, Miorhizomys, Anepsirhizomys and Rhizomys (Brachyrhizomys)) in Africa, Thailand, Afghanistan, Pakistan, India, and China.

The systematic position of the rhizomyines is controversial. Some authors have placed them in a distinct Family Rhizomyidae (Miller and Gidley, 1918; Ellermann, 1940, 1941; Simpson, 1945; Ellerman and Morrison-Scott, 1951, 1966; Colbert and | Hooijer, 1953; Flynn 1982a, 1982b, 1990, 1993; Flynn and Guo-qinQi, 1982; Flynn and Sabatier, 1984; Flynn et al., 1983, 1995; Alemseged and Geraads, 2000; Wessels and de Bruijn, 2001), including the tachyoryctines with them. Other authors considered the rhizomyines as members (Lydekker, 1885; Palmer, 1897; Colbert, 1935) or a subfamily (Thomas, 1896; Tullberg, 1899; Musser and Carleton, 2005; Flynn, 2009) of the Spalacidae. As Winge (1887) originally did when he created the Tribe Rhizomyini, some other specialists considered the rhizomyines as a tribe within the Muridae. McKenna and Bell (1997) considered the rhizomyines a subfamily within the Muridae | and subdivided it into two tribes: the Rhizomyini and the Tachyoryctini. The results of 
recent analyses of mitochøndrial and nuclear genes support a monøphyletic Spalacinae plus Rhizomyinae, with Myospalacinae as sister group (Jansa and Weksler, 2004; Gogolevskaya et al., 2010) and leave little doubt about the inclusion of the rhizomyines in the Family Spalacidae.The results of recent analyses of nucleotide sequences support a monophyletic Spalacinae plus Rhizomyinae, with Myospalacinae as sister group (Norris et al., 2004; Gogolevskaya et al., 2010; see also Jansa and Weksler, 2004) and leave little doubt about the inclusion of the rhizomyines in the Family Spalacidae.

The similarity in many morphological traits among the three subfamilies probably stems from their common origin (Gogolevskaya et al., 2010) as well as convergence to a fully subterranean way of life through geological time.

However, the relationships within the rhizomyines (Asian bamboo rats and African mole rats) remain unclear. Some authors considered that the Asian rhizomyines are distantly related to the African representatives of the group (Endo et al., 2001; Musser and Carleton, 2005) and, therefore, they separate them into two different subfamilies: the Rhizomyinae (Asian) and the Tachyoryctinae (African). Other rodentologists considered that African fossil rhizomyines do not appear far from the Asian ones from a morphological viewpoint and they include them in a single subfamily, the Rhizomyinae (McKenna and Bell, 1997; Flynn, 2009; López-Antoñanzas, 2012; López-Antoñanzas and Wesselmann, in press). Furthermore, the origin of Tachyoryctes is controversial. Some authors advocated an independent African origin for this taxon (Ellerman, 1940, 1941; Lavocat, 1978; Endo et al., 2001), whereas others defended an Asian origin (Black, 1972; Jacobs, 1978; Sabatier, 1978; Munthe, 1980; De Bruijn et al., 1981; Flynn, 1982a, 1986, 1990, 2009; Flynn et al., 1990; Wessels and De Bruijn, 2001; Haile-Selassie et al., 2004; Wesselman et al., 2009). All these yet unresolved issues motivated us to provide a substantiated hypothesis of the mutual relationships within this subfamily based on cladistic methods.

\section{Material and methods}

The study presented herein is based on the examination of original specimens, casts, and Formatted: Indent: First line: $0 "$ data from the literature. We examined the following: skulls of extant Rhizomys sinensis 
(ZMB 16768, ZMB 17413, ZMB 45362, ZMB 43372, ZMB 43373, ZMB 17411, ZMB 16770, ZMB 17417, ZMB 16766 in the MB and C.G.1934-1237, C.G.1912-851 in the MNHN), R. pruinosus (DH. 280, C.G. 1929-259, C.G. 1929-261, C.G.1892-1360, C.G. 1929-263, C.G.1958-724, C.G.1962-2297, C.G.1962-2295, C.G. 1929-266, C.G. 1929272, C.G. 1929-260, C.G. 1929-267, C.G. 1993-48, C.G. 1929-264, C.G. 1937-1251, C.G. 1929-265, C.G. 1929-270, C.G. 1929-340, C.G. 1993-02 in the MNHN), $R$. sumatrensis (ZMB 1847, ZMB A1316, ZMB 38840, ZMB 48085, ZMB 21249 in the MB C.G.1993-49, C.G. 1962-2294, C.G. 2007-162, C.G. 1980-235, A 7.216, A7.215 in the MNHN), Cannomys badius (ZMB 3424, ZMB 44768, ZMB 44769 in the MB and CG-2000-761, CG-1860-382 in the MNHN), Tachyoryctes macrocephalus (ZMB 36656, ZMB 55165, ZMB 36649 in the MB and C.G. 1972-73, C.G. 1972-74, C.G. 1972-75, C.G. 1972-76, C.G. 1974-202 in the MNHN), T. splendens (ZMB 12, ZMB 78, ZMB 79, ZMB 80, ZMB 81, ZMB 83, ZMB 88, ZMB 114, ZMB 117, ZMB 3404, ZMB 3403, ZMB 9015, ZMB 16048, ZMB 28069, ZMB 36601-13, ZMB 36618, ZMB 36620-36621, ZMB 36624-36634, ZMB 36636-36637, ZMB 36640-36646, ZMB 36648, ZMB 36650-36655, ZMB 46257, ZMB 48300, ZMB 72559-72593, ZMB 7721 in the MB and C.G. 1993-217, C.G. 1993-231, C.G. 1993-220, C.G. 1993-238, C.G. 1933-2752, C.G. 2000-685, C.G. 1961-33, C.G. 1972-10, C.G. 1972-27, C.G. 1972-39, C.G. 1972-51, C.G. 1972-64, C.G. 1972-65, C.G. 1972-68, C.G. 1993-222, C.G. 1993225, C.G. 1993-241, C.G. 1993-246, C.G. 1993-250, C.G. 1993-253, C.G. 1993-254, C.G. 1993-257, C.G. 1993-263, C.G. 1993-265, C.G. 1993-268, C.G. 1993-272, C.G. 1993-274, C.G. 1993-289, C.G. 1993-302, C.G. 1993-303, C.G. 1993-308, C.G. $1993-$ 323, C.G. 1933-2746, C.G. 1933-2756, C.G. 1905-385, C.G. 1933-2745, C.G. $1933-$ 2748, C.G. 1960-454, C.G. 1962-2292, C.G. 1970-210, C.G. 1972-16, C.G. 1972-19, C.G. 1972-44, C.G. 1972-46, C.G. 1972-50, C.G. 1972-54, C.G. 1972-58, C.G. $1993-$ 221, C.G. 1993-223, C.G. 1993-232, C.G. 1993-238, C.G. 1993-245, C.G. 1993-281, C.G. 1993-288, C.G. 1993-294, C.G. 1993-304, C.G. 1993-307, C.G. 1993-318, C.G. 1993-322, C.G. 1960-453, C.G. 1962-2290, C.G. 1972-14, C.G. 1972-25, C.G. $1972-$ 29, C.G. 1972-41, C.G. 1972-57, C.G. 1974-202, C.G. 1991-629, C.G. 1993-217, C.G. 1993-224, C.G. 1993-239, C.G. 1993-240, C.G. 1993-249, C.G. 1993-261, C.G. 1993270, C.G. 1993-292b, C.G. 1993-295, C.G. 1993-296, C.G. 1993-316, C.G. 1961-921, C.G. 1972-11, C.G. 1972-15, C.G. 1972-17, C.G. 1972-24, C.G. 1972-33, C.G. $1972-$ 
37, C.G. $1972-45$, C.G. 1972-52, C.G. 1972-53, C.G. 1972-69, C.G. 1981-533, C.G. 1988-119, C.G. 1993-226, C.G. 1993-227, C.G. 1993-228, C.G. 1993-230, C.G. $1993-$ 235, C.G. 1993-237, C.G. 1993-242, C.G. 1993-247, C.G. 1993-259, C.G. 1993-260, C.G. 1993-267, C.G. 1993-283, C.G. 1993-284, C.G. 1993-286, C.G. 1993-287, C.G. 1993-309, C.G. 1993-310, C.G. 1993-315, C.G. 1993-317, C.G. 1993-320, C.G. 19332747, C.G. 1972-06, C.G. 1972-21, C.G. 1972-26, C.G. 1972-30, C.G. 1972-34, C.G. 1972-43, C.G. 1972-59, C.G. 1972-62, C.G. 1972-66, C.G. 1972-67, C.G. 1993-231, C.G. 1993-234, C.G. 1993-236, C.G. 1993-256, C.G. 1993-275, C.G. 1993-278, C.G. 1993-285, C.G. 1993-290, C.G. 1993-291, C.G. 1993-300, C.G. 1993-305, C.G. $1993-$ 314, C.G. 1962-2291, C.G. 1972-09, C.G. 1972-12, C.G. 1972-31, C.G. 1972-35, C.G. 1972-40, C.G. 1972-47, C.G. 1972-61, C.G. 1988-242, C.G. 1993-219, C.G. 1993-220, C.G. 1993-248, C.G. 1993-251, C.G. 1993-258, C.G. 1993-262, C.G. 1993-273, C.G. 1993-276, C.G. 1993-282, C.G. 1993-299, C.G. 1993-313, C.G. 1993-321, C.G. 19332749, C.G. 1972-18, C.G. 1972-20, C.G. 1972-23, C.G. 1972-42, C.G. 1972-48, C.G. 1972-55, C.G. 1972-56, C.G. 1972-71, C.G. 1993-218, C.G. 1993-229, C.G. 1993-243, C.G. 1993-264, C.G. 1993-269, C.G. 1993-271, C.G. 1993-277, C.G. 1993-279, C.G. 1993-292, C.G. 1993-297, C.G. 1993-298, C.G. 1993-306, C.G. 1993-311, C.G. 1993319, C.G. 1993-324, C.G. 1972-07, C.G. 1972-08, C.G. 1972-13, C.G. 1972-22, C.G. 1972-28, C.G. 1972-32, C.G. 1972-36, C.G. 1972-38, C.G. 1972-49, C.G. 1972-60, C.G. 1972-63, C.G. 1972-70, C.G. 1993-233, C.G. 1993-244, C.G. 1993-252, C.G. 1993-255, C.G. 1993-266, C.G. 1993-280, C.G. 1993-293, C.G. 1993-301, C.G. $1993-$ 312, C.G. 1933-2752, in the MNHN), isolated teeth, maxillary fragments and mandible fragments of the following extinct species: Prokanisamys arifi (casts of HGSP-116-22, HGSP-116-371, HGSP-116-83, HGSP-116-101, HGSP-116-123, HGSP-116-125, HGSP-116-14, HGSP-116-37, HGSP-116-42, HGSP-116-52, HGSP-116-61 in the BSP), Kanisamys indicus (casts of GSI-D271 in the BSP), K. nagrii (casts of AMNH 30.000 and AMNH 39323 in the BSP), K. potwarensis (AMNH 39321), Rhizomyides punjabiensis (AMNH 19762 and cast of GSI-D287 in the BSP), R. sivalensis (casts of D97, D275 and BM (NH) 15926 in the BSP) Protachyoryctes tatroti (cast of GSI-D272 in the BSP), Anepsirhizomys pinjoricus (casts of GSI-D278 and GSI-D280 in the BSP), Miorhizomys nagrii (casts of GSI-D273 and GSI-D285 in the BSP), M. tetracharax (upper incisor of AMNH 39326, cast of AMNH 39325 in the BSP), M. pilgrimi (lower 
incisor of AMNH 39327 and cast of D-278 in the BSP). In addition, we reviewed unpublished original material of the following taxa recovered under the Harvard University-Geological Survey of Pakistan field program on the Potwar Plateau, Pakistan from 1994-2000: Prokanisamys major, Kanisamys indicus, K. potwarensis, K. nagrii, K. sivalensis, and Rhizomyides punjabiensis.

First, second, and third lower molars are designated as $\mathrm{m} 1, \mathrm{~m} 2$, and $\mathrm{m} 3$, respectively, and first, second, and third upper molars as M1, M2, and M3, respectively. The terminology used in the tooth descriptions follows the rodent dental terminology of Mein and Freudenthal (1971), with some adjustments, and Flynn (1982a) (see Fig. 2).

The cladistic analysis treated as ingroup all extant and fossil species of this subfamily known to date. The taxonomic units chosen are the valid species of Rhizomyini and Tachyoryctini, namely Rhizomys sumatrensis, $R$. sinensis, $R$. pruinosus, $R$. (Brachyrhizomys) shansius, R. (Brachyrhizomys) shajius, Cannomys badius, Miorhizomys nagrii, M. micrus, M. blacki, M. pilgrimi, M. harii, M. tetracharax, M. choristos, Protachyoryctes tatroti, Tachyoryctes makooka, T. konjiti, T. pliocaenicus, T. macrocephalus, $T$. splendens, Rhizomyides sivalensis, $R$. punjabiensis, $R$. carbonnelli, R. platytomeus, R. mirzadi, Kanisamys indicus, K. nagrii, K. sivalensis, K. potwarensis, Eicooryctes kaulialensis, Anepsirhizomys opdykei, A. pinjoricus, Pronakalimys andrewsi, Nakalimys lavocati, Prokanisamys kowalskii, P. arifi, P. benjavuni and $P$. | major, $P$. sp. (Jebel Zelten), (see Supplementary File 1"Systematics" below).

Debruijnia arpati, a basal Spalacinae according to the phylogenetic analysis of Flynn (2009), is selected as outgroup. A total of 44 phylogenetically informative characters (mainly of dental morphology) have been coded-(Supplementary File 1). 24 characters are binary, whereas 20 are multistate. Owing to the lack of a priori information, all characters were unordered and equally weighted (Fitch optimality criterion). As some species are known so far from only a few specimens, the influence of intraspecific variation in the scoring of the characters could not be assessed.

1. Hypsodonty: Crown height on at least one side of the tooth greater than length or width of the tooth. This character has been scored as (0) absent; (1) moderate; (2) high.

2. Size: Length of the m2: (0) $1.5-2.5 \mathrm{~mm}$; (1) $2.5-3.5 \mathrm{~mm}$; (2) $3.5-4.5 \mathrm{~mm}$; (3) $4.5-$ $5.5 \mathrm{~mm} ;(4)>5,5 \mathrm{~mm}$ 3. Lophodonty: (0) weak; (1) moderate; (2) high 
4. Masseteric crest: (0) with long anterior extension (1) with short anterior extension (2) without anterior extension

5. Lower masseteric crest: $(0)$ inflated under $\mathrm{m} 2 ;(1)$ not inflated

6. Dentary depth: (0) Shallow; (1) Moderate; (2) Deep

7. Infraorbital foramen: (0) with ventral slit; (1) with abbreviated ventral slit; (2) without ventral slit

8. Longitudinal ornamentation on the $i:(0)$ double ridge; (1) single ridge; (2) $\underline{\text { absent }}$

9. Anteroconid on the m1: (0) discernible); (1) absent (fused with the anterolophid)

10. Mure on the ml: (0) present; (1) constricted; (2) absent.

11. Labial anterolophid on the $\mathrm{ml}:$ (0) present; (1) absent

12. Mesolophid on the m1: (0) long and complete and separated from the hypolophid; (1) short and well-separated from the hypolophid; (2) short and migrated towards the hypolophid; (3) absent; (4) a long continuation of the protoconid

13. Posterior protoconid-metaconid connexion on the m1: (0) present; (1) absent

14. Anterosinusid on the ml: (0) present; (1) absent

15. Mure on the m2: (0) present; (1) constricted; (2) absent

16. Mesolophid on the m2: (0) long and complete and separated from the hypolophid; (1) short and well-separated from the hypolophid; (2) short and migrated towards the hypolophid; (3) absent; (4) a long continuation of the protoconid

17. Labial anterolophid on the $\mathrm{m} 2$ : (0) present; (1) absent

18. Hypolophid on the m2: (0) not isolated; (1) isolated

19. Protosinusid on the m2: (0) present; (1) absent

20. Anterosinusid on the m2: (0) present; (1) absent

21. m3: (0) Reduced (shorter than the m2); (1) Enlarged (equal or larger than the $\underline{\mathrm{m} 2)}$

22. Labial anterolophid on the m3: (0) present; (1) absent

23. Mure on the m3: (0) present; (1) absent

24. Mesolophid on the m3: (0) long and complete and separated from the hypolophid; (1) short and well-separated from the hypolophid; (2) short and migrated towards the hypolophid; (3) absent; (4) a long continuation of the protoconid 
25. Posterosinusid on the m3: (0) large; (1) small; (2) absent (posterolophid fused with hypolophid)

26. Entoconid on the m3: (0) not isolated; (1) isolated

27. Protosinusid on the m3: (0) present; (1) absent

28. Anterosinusid on the m3: (0) present; (1) absent

29. Roots on the M1: (0) three; (1) four; (2) Hypselodont. The development of four roots on the M1 is a modern Rhizomyinae trait

30. Protosinus on the M1: (0) present; (1) absent

31. Mesoloph on the M1: (0) absent; (1) short; (2) long and complete; (3) long and complete but divided with a buccal cusp

32. Mesostyle on the M1: (0) may be present; (1) absent

33. Ectoloph on the M1: (0) present; (1) absent

34. Anterocone on the M1: (0) distinct; (1) fused with the anteroloph

35. Metaloph on the M1: (0) present and distinct from the posteroloph; (1) fused with the posteroloph

36. Posterosinus on the M1: (0) present; (1) absent

37. Mesoloph on the M2: (0) absent; (1) short; (2) long and complete; (3) long and complete but divided with a buccal cusp

38. Longitudinal crest on the M2: (0) present; (1) absent

39. Ectoloph on the M2: (0) present; (1) absent

40. Metaloph on the M2: (0) present and distinct from the posteroloph; (1) early fused with the posteroloph; (2) absent

41. Posterosinus on the M2: (0) present; (1) absent

42. Anterosinus on the M3: (0) open; (1) enclosed by anteroloph and paracone; (2) $\underline{\text { absent }}$

43. Mesoloph on the M3: (0) absent; (1) short; (2) long and complete; (3) long and complete but divided with a buccal cusp

\section{Posterior lake on the M3: (0) large; (1) small; (2) absent}

The data matrix (Table 1) was built under Mesquite 2.6 (Maddison and Maddison, 2009) and processed with TNT (Goloboff et al., 2008) with the "traditional search" option (using TBR). Branch support was estimated through two complementary indices: 
Bremer Support (Bremer, 1994) and Relative Bremer Support (Goloboff and Farris, 2001).

\section{Abbreviations:}

AMNH: American Museum of Natural History, New York; BAM: Bamian, Afghanistan; BMNH: The Natural History Museum, London, England; BSP: Bayerische Staatssammlung für Paläontologie und Historische Geologie, Munich, Germany; C.G: Catalogue général du Laboratoire des Mammifères et Oiseaux, MNHN, Paris, France; DMR: Department of Mineral Ressources, Bangkok, Thailand; FSL: Université Claude Bernard-Lyon 1, Villeurbanne, France; GSI, Geological Survey of India, Calcutta, India; H-GSP: Howard University-Geological Survey of Pakistan; IVAU: Department of Earth Sciences, Utrecht University, Utrecht, Netherlands. IVPP: Institute of Vertebrate Palaeontology and Palaeoanthropology, Beijing, China; KNM: Kenya National Museums, Nairobi, Kenya; MNHN: Muséum national d'Histoire naturelle, Paris, France; NME: National Museum of Ethiopia, Addis Ababa, Ethiopia; PMAE: Peabody Museum of Archaeology and Ethnology, Cambridge, USA; PMNH: Pakistan Museum of Natural History, Islamabad, Pakistan; PEC: Pul-e Charkhi, Kabul, Afgahnistan; SMF: Mammalogie-Sammlung, Forschungsinstitut und Naturmuseum Senckenberg, Frankfurt am Main; UM2: Université des Sciences et Techniques du Languedoc-Montpellier 2, Montpellier, France; Y-GSP: Yale-Geological Survey of Pakistan, Quetta, Pakistan; YPM: Yale Peabody Museum of Natural History, New Haven, USA; Z: Zinda Pir area, Pakistan; ZMB: Zoologische Sammlung, Museum für Naturkunde der Humboldt-Universität, Berlin, Germany;

\section{Systematics}

Asian rhizomyines are widespread. They live in China, northern and northeastern India, Nepal, Bhutan, southeastern Bangladesh, Myanmar, Laos, Thailand, Cambodia, Vietnam, Malaysia and Sumatra (Fig. 1) where they are known from a wide variety of habitats (from bamboo forest to cultivated land, and up to $4000 \mathrm{~m}$ elevation) (IUCN, 
2010). African rhizomyines are nowadays discontinuously distributed in the centre and, especially, the eastern part of the continent (Democratic Republic of the Congo, Uganda, Rwanda, Burundi, Tanzania, Kenya, Ethiopia, Somalia and possibly South Sudan and Eritrea) (Fig. 1) and they are also recorded from a wide variety of habitats (tropical moist forest and open woodland to savanna, grasslands and agricultural and pasture areas, sometimes above $4000 \mathrm{~m}$ ) (IUCN, 2010).

Musser and Carleton (1993, pp. 685, 2005, pp. 913-915) have provided a census of the extant species of Rhizomys and Cannomys recognized as valid (see also Ellerman and Morrison-Scott, 1951, pp. 550-553, 1966, pp. 521-522). They concluded that 3 species of Rhizomys and a single species of Cannomys are well defined at present: Rhizomys sinensis, $R$. pruinosus, $R$. sumatrensis and Cannomys badius. The taxonomy of Tachyoryctes is more controversial and the number of species included in this taxon ranges from 14 (Allen, 1939, pp. 361-363; Ellerman, 1941) to 2 (Misonne, 1971, p. 7; Rahm, 1980, pp. 23-27; Bucher, 1982, p. 478; Corbet and Hill, 1991). Musser and Carleton (1993, pp. 685-687; 2005, pp. 922-926) considered that the drastic reduction from 14 to 2 species deserves systematic attention, that has never been performed and therefore they cautiously recognized 11 (Musser and Carleton, 1993) and-or 13 (Musser and Carleton, 2005) species. However, the recent morphometric approach given by Beolchini and Corti (2004) supports the hypothesis of Misonne (1971) of recognizing only 2 species in the genus Tachyoryctes: T. macrocephalus and T. splendens. Because our analysis is morphological, we evaluate these two species only, although we admit that $T$. splendens might actually be a cryptic species complex.

The morphology of the teeth of fossil rhizomyines has been described in detail (Colbert, 1933, 1935; Teilhard de Chardin, 1942; Bohlin, 1946; Colbert and Hooijer, 1953; Black, 1972; Jacobs, 1978; Sabatier, 1978, 1979, 1982; Brandy, 1979a, 1979b; Munthe, 1980; de Bruijn et al., 1981; Flynn, 1982a, 1982b, 1983, 1993, 2009; Flynn | and Guo-qinQi, 1982; Wessels et al., 1982, 2003, 2008; Flynn et al., 1983, 1990; Sen, 1983; Flynn and Sabatier, 1984; Mein and Ginsburg, 1985, 1997; Tong and Jaeger, 1993; Lindsay, 1996; Wessels and de Bruijn, 2001; Wesselman et al., 2009; LópezAntoñanzas and Wesselman, in press). Therefore, in this work, we only describe the teeth of the three modern genera and give a short historical background for the fossil ones as well as some pertinent additional details. 


\section{Genus Rhizomys Gray, 1831. Type species: Rhizomys sinensis Gray, 1831}

Referred species: Rhizomys pruinosus, $R$. sumatrensis

On the basis of a skull and skin of a glirine quadruped brought from China by the amateur naturalist J. Reeves, Gray (1831, p. 95) described the new genus Rhizomys as follows: "Dentes primores 2/2 maximi, elongati, triangulares, acutati: molares 3/3 3/3 radicati, subcylindrici, coronis transversim subparallelim porcatis; superiores internè lobati. Caput magnum. Oculi parvi aperti. Auricula nuda conspicua. Corpus crassum subcylindricum. Pedes breves validi, digitis 5-5. Cauda mediocris, crassa, nuda”. That is: Incisors $2 / 2$ very large, elongate, triangular, pointed: molars $3 / 3$ three rooted, subcylindrical, with crowns with transversal subparrallel furrows; upper teeth lobated internally. Head large. Eyes small open. External ears naked visible. Body massive subcylindrical. Feet short robust, with 5-5 digits. Tail average, thick, naked.

Rhizomys sinensis Gray, 1831. Gray (1831) recognized the new genus and new species of rodent Rhizomys sinensis. The brief Latin diagnosis he gave (Gray, 1831: 95):“Rhiz. pallidè cinerascens unicolor" can be translated as follows: "Rhiz. pale ashgrey single-colored". The type specimens are BMNH 49b (skin) and BMNH 1161a (skull) (P. Jenkins, pers. comm. 2012).

The molars of Rhizomys sinensis are short rooted and lack the mure. They show unilateral hypsodonty and a strong wear gradient with first molars well worn by the time the third molars erupt (Fig. 3A-B). The orange upper incisors are recurved and ventrally directed and lack major ornamentation. M2 and $\mathrm{m} 2$ are the largest teeth of the upper and lower tooth row, respectively. The dental pattern of the upper molars is tetralophodont with four lophs (anteroloph, protoloph, mesoloph, and metaloph+posteroloph). By wear, the labial reentrants are closed-off and three enamel lakes are isolated. The central one may be confluent with the lingual reentrant, forming a narrow and elongated central reentrant that may divide the tooth into two parts. The lower molars are lower crowned than the upper ones. M1 undergoes heavy wear earlier than posterior molars; the latter continue to erupt past its occlusal surface until, in old age, the molars are worn to the same level. The lower incisors lack major ornamentation 
and their enamel is flat. The mandibular foramen is well posterior to the distal part of $\mathrm{m} 3$ (located a little above the $\mathrm{m} 3$ at the level of the tip of the coronoid process). The mental foramen is situated anteriorly to the anterior part of $\mathrm{m} 1$ at about the midline of the dentary. The pattern of $\mathrm{m} 1$ is pentalophodont (anterolophid, metaconid, mesolophid, hypolophid, and posterolophid) whereas $\mathrm{m} 2$ and $\mathrm{m} 3$ show four major lophs (anterolophid-metalophid, mesolophid, short hypolophid, and long posterolophid). With wear, the lingual and labial reentrants close off, isolating various enamel lakes, the | number of which depending depends on the state of wear of the teeth.

Rhizomys sumatrensis (Raffles, 1821). Raffles (1821, p. 258) named this species as Mus sumatrensis on the basis of a drawing and a specimen forwarded from Malacca (Malasya) by W. Farquhar. The reason he chose sumatrensis as a species name when, by that time, it had not been found in Sumatra remains unknown. He gave the following diagnosis (Raffles, 1821, p.258): "The body is about seventeen inches in length, ten inches in circumference, and the height at the shoulder about five. The tail is six inches long, tapering, and blunt at the points, naked and scaly. The body is covered with rough greyish hair, brownish on the back. The head round and lighter coloured. Incisors large, two in each jaw. Eyes small. Ears naked. Fore-feet four-toed; hind-feet with a short fifth toe." Later on, Gray (1831, p. 95) included Mus sumatrensis in the new genus Rhizomys and he gave the following brief Latin diagnosis: "Pallidè fuscus, pilis raris albidis interspersis; corporis lateribus pedibusque saturatioribus; genis pallidioribus, occipite nigrescenti lineâ longitudinali albâ, pectore albido". This can be translated as: "Pale brown, with some hairs scattered whitish; with body broad and feet darker; with cheeks paler, back of the head blackish with a white longitudinal stripe, chest whitish". The type specimen was possibly lost in transit (P. Jenkins, pers. comm. 2012).

The teeth of Rhizomys sumatrensis and $R$. sinensis are quite similar and only a few differences can be discerned.The molars of $R$. sumatrensis are high crowned, although not as high as those of $R$. sinensis, but they have longer roots and much smaller M3 than $R$. sinensis. Furthermore, M1 of $R$. sumatrensis is the largest tooth, whereas in $R$. sinensis it is $\mathrm{M} 2$. 
Rhizomys pruinosus Blyth, 1851. This species was named by Blyth (1851, p. 519) after the examination of specimens collected by R. Frith in the Khasi hills (Cherrapunji, India). Blyth differentiated this species from $R$. sumatrensis in being "much less robust, having a much shorter tail, and a dense coat of fine soft fur instead of a thin coat of bristly fur". However, he pointed out that their structural characters were essentially the same. The syntypes are supposed to be in the collection of the Indian Museum, Kolkata (P. Jenkins, pers. comm. 2012), but we were unable to obtain confirmation.

The dental pattern of the teeth of $R$. pruinosus is similar to that of the remaining species of the genus. There is only a minor difference concerning the smaller size of the molars.

Rhizomys (Brachyrhizomys) shansius (Teilhard de Chardin, 1942). Teilhard de Chardin (1942), on the basis of four lower mandibles from the Pliocene of Taoyang (Yushe Basin, Shanxi, China) named the new genus Brachyrhizomys, which was seen as a primitive type of Rhizomys, and the new species B. shansius. Later on, Flynn (2009) after a complete and detailed study of this species concluded that, even though it is distinct from all living species of Rhizomys, it is sufficiently closely related to them for Brachyrhizomys to be treated as a subgenus within Rhizomys (see Fig. 4F-G). The holotype of this species, IVPP 31.096, a right dentary with incisor, is housed in the IVPP. Additional material of this species has been found at other localities of the Yushe Basin (Flynn, 1993; Flynn, 2009).

Rhizomys (Brachyrhizomys) shajius Flynn, 1993. The holotype and only known specimen of this taxon (V8920), a right dentary fragment with $\mathrm{m} 2-\mathrm{m} 3$ comes from the Late Miocene YS 156 locality of the Tancun subbasin (south of Yushe) (Flynn, 1993). Smaller than B. shansius, it is housed in the IVPP.

Genus Cannomys Thomas, 1915a. Type species: Cannomys badius (Hodgson, 1841)

Cannomys badius (Hodgson, 1841). This species was coined as Rhizomys badius by Hodgson (1841, p. 60) on the basis of a male specimen obtained from "some miles north of the great valley" of Nepal. He gave the following brief Latin 
diagnosis:"Unicolor: pilis internē nigri cantibus schistaceis: longitudo Corporis 8 uncia, cauda 2 5/8, capitis 2 1/4: Pedis antici (cum ungue) 1 1/16: pedis postici 13/8, auricula $1 / 4$ ". This can be translated as: "One-colored: with hairs internal blackish slatecolored: length of body 8 inches, tail 25/8, head $2 \frac{1 / 4}{4}$ : anterior foot (with claw) 11/16: posterior foot $13 / 8$, external ear $1 / 4$ ". The type specimen is BMNH 1843.1.12.61 (skin and skull) (P. Jenkins, pers. comm. 2012).

Later on, Thomas (1915a) created the new genus Cannomys for which he took Rhizomys badius as type, but in which he also included two species now seen as junior synonyms. He gave the following diagnosis: "Size comparatively small. Palm and solepads normal, well defined, not granulated. Mammæ 2-2=8. Anteorbital foramina and posterior nares much as in Rhizomys. Incisors forming a segment of a large circle, their points thrown strongly forwards. Molars decreasing in size backwards, the first decidedly larger than the second, its grinding surface not worn lower than that of the latter". The species Cannomys pater coined by Thomas (1915b) is today also considered a junior synonym of $C$. badius (Musser and Carleton, 2005).

The upper molars of Cannomys badius show unilateral hypsodonty. The upper incisors are proodont and lack major ornamentation. The dental pattern of the M1 is tetralophodont (protocone-anteroloph, protocone-protoloph, hypocone-mesoloph and hypocone-metaloph-posteroloph), whereas the M2 and M3, much shorter than the M1, only have three transverse lophs (protocone-anteroloph-protoloph, hypocone-mesoloph and hypocone-metaloph-posteroloph) (Fig. 3D). Through wear, the lophs join at the margin of the tooth isolating two transversely elongated enamel lakes. The lower molars are lower crowned than the upper ones. The lower incisors lack major ornamentation and their enamel is flat. The mandibular foramen is well posterior to the distal side of the $\mathrm{m} 3$ (it is located a little higher than the $\mathrm{m} 3$ at the level of the extremity of the coronoid process). The mental foramen is situated anteriorly to the anterior side of the $\mathrm{m} 1$ at about the midline of the dentary. The dental pattern of the $\mathrm{m} 1$ is pentalophodont with five transverse lophids (anterolophid, protoconid-metalophid, protoconidmesolophid, hypoconid-hypolophid and hypoconid-posterolophid), whereas that of the $\mathrm{m} 2$ and $\mathrm{m} 3$ has three lophids (anterolophid-metalophid, mesolophid and hypolophidposterolophid) (Fig. 3C). By wear, all lingual reentrants are closed off forming lingual enamel lakes. 
| Genus Tachyoryctes (Rüppell, 1836). Type species: Tachyoryctes splendens (Rüppell, 1836)

Referred species: Tachyoryctes macrocephalus, Tachyoryctes konjiti, Tachyoryctes pliocaenicus, Tachyoryctes makooka.

Tachyoryctes splendens Rüppell, 1836. Rüppell (1836, p.36) named a new species of rodent that he discovered in Ethiopia (Fig. 5). In his work he pointed out that this rodent resembled very much Bathyergus from Cape of Good Hope in the skull, crown and size of the teeth, toes and claws. However, he also noticed some singularities in the Ethiopian animal like the small size of its pinna and its longer and more rounded tail. Since very few specimens of the genus Bathyergus were known at that time, he refrained from naming a new genus, even though unnamed eminent Londoner and Parisian experts thought otherwise. Nevertheless, in case someone wanted to transfer his species into a new genus, he added as a footnote the following thought: "Will man mit aller Gewalt diese Thier zu einer eigenen Gattung erheben, so dürfte man solche

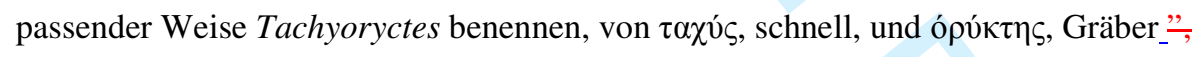
which means-("If one would by any means erect a new genus for this animal, he might

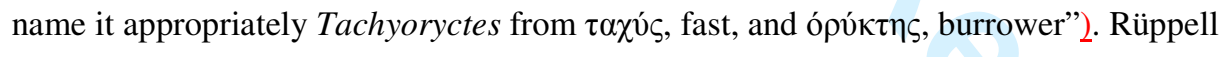
(1842) reallocated this species to the genus Rhizomys including in it the new taxon Rhizomys macrocephalus (see below) as well. The genus Tachyoryctes was accepted in Heck (1851a, p.464) in a section written by C. Girard (Heck, 1851b, p. v). Heuglin and Fitzinger (1866, pp.32-33) and later authors also accepted Tachyoryctes as valid and included both $T$. splendens and T. macrocephalus in it. The lectotype of T. splendens is SMF 4317 (head and skin).

Tachyoryctes splendens has ever growing teeth showing unilateral hypsodonty. Upper and lower incisors are orange and flattened, and the lower incisor has a prominent ridge. The proodont upper incisors may also bear a fine longitudinal ridge. The upper molars lack the mure and the the anterior part of the teeth is isolated from the posterior one. When unworn, the M1 show a long anteroloph, a distinct and isolated protoloph, a long mesoloph that joins the hypocone and a metacone that connects 
labially to a short posteroloph. The morphology of the M2 and M3 is similar to that of the M1 except for the anterior part of the teeth in which there is a single anterior crest (anteroloph-protoloph) (Fig. 3F). Rapidly during wear, the lophs join at the margin of the tooth isolating three (on the M1) or two (on the M2 and M3) enamel lakes, which will disappear with further attrition. When unworn, the $\mathrm{m} 1$ shows a cuspid-like isolated anterolophid, an isolated metaconid, the entoconid connected to the protoconid and an arcuate posterolophid, which is a long continuation of the hypoconid. The $\mathrm{m} 2$ and $\mathrm{m} 3$ have the anterolophid fused with the metaconid and the teeth show three oblique lophids (anterolophid-metaconid, entoconid-protoconid and hypoconid-posterolophid). The mure is lacking (Fig. 3G).

Tachyoryctes macrocephalus (Rüppell, 1842). Rüppell (1842) named the new species Rhizomys macrocephalus on the basis of a rodent from Shoah province-Province (southern Ethiopia) that was sent to him. The lectotype is SMF 4318 (skull and skin). This species was soon reallocated to the genus Tachyoryctes (see above). The morphology of the cheek teeth of T. macrocephalus is similar to that seen in $T$. splendens. The difference between these taxa rests in the much greater size of the former.

Tachyoryctes pliocaenicus Sabatier, 1978. This species was named on the basis of eight mandibles (some of them incomplete) and a fragmentary skull with right and left M1-M2 from the Pliocene Hadar Formation, Ethiopia (Sabatier, 1978). The holotype, a right mandible with m1-m3 (AL.288.29), is housed in the NME.

Tachyoryctes konjiti Sabatier, 1982. This taxon was named by Sabatier (1982; see also Sabatier, 1979) on the basis of a hundred isolated molars from the Pleistocene locality of Garba VIII (Melka Kunturé, Ethiopia). Its holotype (Garba VIII B 16), an isolated M1, is housed in the NME. Additional material of $T$. konjiti has been found in other Pleistocene Ethiopian localities as Garba IV, Gombore I $\gamma$, Simbiro, Gombore II B/C, Garba III E, Garba X and Garba VIIIB (Sabatier, 1979; Galloti et al., 2010). 
Tachyoryctes makooka Wesselman, Black et Asnake, 2009. This taxon was coined on the basis of various mandibles, maxillary fragments, isolated molars as well as some postcranial elements (Wesselman et al., 2009). Its holotype comes from the Late Miocene Digiba Dora Vertebrate Locality 1 (Middle Awash, Ethiopia) and is housed in the NME. This species has been also recovered from various Late Miocene-Pliocene localities of the Middle Awash (ALA-VP-2, AME-VP-1, AMW-VP-1, ASK-VP-3, GAW-VP-1, GAW-VP-3, KUS-VP-1, STD-VP-2, WKH-VP-1) (Wesselman et al., 2009). The morphology of the teeth of T. makooka has been described in detail by López-Antoñanzas and Wesselman (in press).

Genus Anepsirhizomys Flynn, 1982. Type species: Anepsirhizomys opdykei Flynn, 1982

Referred species: Anepsirhizomys pinjoricus

Anepsirhizomys opdykei Flynn, 1982. This taxon was named on the basis of a left dentary fragment with m1-m2 from the middle Pliocene locality DP70 (Bunha River area, Potwar Plateau, Pakistan) (Flynn, 1982a). Additional material of this species has not been found to date.

Anepsirhizomys pinjoricus (Hinton, 1933). Hinton (1933), in the course of the preparation of a monograph on Indian fossil rodents, which was never actually published, studied some rodent remains belonging to the GSI. This work led him to discover various new species of Rhizomys, one of which he named Rhizomys pinjoricus. Black (1972) reallocated this species to the genus Rhizomyides created by Bohlin (1946), which unfortunately he miswrote as "Rhizomyoides" (see below). It was not until 1990 that this taxon was suspected to be an Anepsirhizomys (Flynn et al., 1990). The holotype of this species (G.S.I. D278), a fragmentary mandible with m2-m3, is from the Late Pliocene of the Simla area, India. It is housed in the BMNH (paleontology collection). Additional material of this species has been recorded from the early Pleistocene near the base of the "Pinjor" strata (Nadah village, Simla Hills, India) (Flynn et al., 1990). 
Genus Miorhizomys Flynn, 2009. Type species: Miorhizomys nagrii (Hinton, 1933)

Referred species: Miorhizomys micrus, M. blacki, M. pilgrimi, M. harii, M. tetracharax, M. choristos.

The detailed study of the oldest fossil skull and postcrania of Rhizomys (Brachyrhizomys) shansius from the Yushe Basin carried out by Flynn (2009) led him to realize that even if Brachyrhizomys from the Siwaliks of the Indian subcontinent share some synapomorphies with the former species (and extant Rhizomys), there are also noteworthy differences between them. Indeed, the Siwalik bamboo rats lack important synapomorphies of living rhizomyines and of $R$. (Brachyrhizomys) shansius like-such as a high infraorbital foramen without open ventral slit (Flynn, 2009). Thus, he created the new genus Miorhizomys for large Siwalik bamboo rats and their Miocene relatives from southern China.

Miorhizomys nagrii (Hinton, 1933). Hinton (1933) on the basis of some remains he found among the material belonging to the GSI named four new species, which he considered as belonging to the genus Rhizomys. One of them was Rhizomys nagrii, which was based on a left dentary fragment with broken i and m2-m3 (GSI D273) from the Late Miocene lower alternations of Haritalyangar, Simla Hills, India. Black (1972) described in detail the material briefly diagnosed by Hinton (1933). In his revision, Black transferred this species to the genus Rhizomyides Bohlin, 1946, mispelling as Rhizomyoides (see below). Afterwards R. nagrii was reallocated to Brachyrhizomys (Flynn, 1982a). When Flynn (2009) named the new genus Miorhizomys he designated this as its genotypic species. The holotype of this taxon is housed in the BMNH (paleontology collection).

Additional material of this species has been recorded from the Late Miocene of Kaulial, Pakistan, as well as from localities Y270, Y260, Y182, Y330, Y261, Y317, Y464, Y262, Y892 of the lower Dhok Pathan Fm., Potwar Plateau, Pakistan (Flynn 1982a) and from the coeval vertebrate locality of Lufeng (about $9 \mathrm{~km}$ north of Lufeng city) in southern China (Flynn and Qi, 1982). Furthermore, various $\underline{\text { Several isolated }}$ molars of Miorhizomys nagrii described by Jacobs (1978) under the name Rhizomyoides cf. R. nagrii had beenwere collected and described by Jacobs (1978) by him atfrom the Late Miocene Dhok Pathan hominoid locality YGSP 182A, about 9.2 Myr. 
Miorhizomys micrus (Flynn, 1982). The holotype and sole specimen recorded of this species (YGSP 5494) is a left dentary fragment with broken i1, m1-m3 from the Late Miocene (9.3 Myr) lower Dhok Pathan Formation in the Potwar Plateau, Pakistan (Flynn 1982a). The taxon was originally ascribed to Brachyrhizomys, but was reallocated to Miorhizomys by Flynn (2009). This material is currently housed at the PMAE and it should eventually be returned to Pakistan and be deposited at the PMNH.

Miorhizomys blacki (Flynn, 1982). Brachyrhizomys blacki was named by Flynn (1982a) on the basis of a single right dentary fragment with broken i1, m2-m3 recorded from the Late Miocene locality Y464 of the Dhok Pathan Formation in the Potwar Plateau, Pakistan. The taxon was originally ascribed to Brachyrhizomys, but was reallocated to Miorhizomys by Flynn (2009). This specimen is currently housed at the PMAE and it should eventually be deposited at the PMNH. Unfortunately no additional material of this species has been found to date.

Miorhizomys pilgrimi (Hinton, 1933). In 1933, Hinton named the new species Rhizomys pilgrimi for a partial right mandible with $\mathrm{m} 2-\mathrm{m} 3$ from the late Miocene lower alternations, Haritalyangar, India. This taxon has known the same taxonomic history as Miorhizomys nagrii. The holotype is housed in the BMNH (paleontology collection). $M$. cf. pilgrimi has been found at the Late Miocene (9.4-7.9 Myr) localities Y270, Y17, Y19, Y118, Y954, Y992, and Y1000 of the Dhok Pathan Formation in the Potwar Plateau, Pakistan (Flynn, 1982a), and at the coeval Chinese locality of Lufeng (Flynn and Qi, 1982).

Miorhizomys harii (Prasad, 1968). This taxon was named based on a single right dentary fragment with $\mathrm{m} 1-\mathrm{m} 2$ recovered from Haritalyangar, India. Its age is unknown, but Flynn (1982b) suggested an age close to $9 \mathrm{Myr}$ (current time scale) on the basis of its stage of evolution. This species was originally considered as belonging to the genus Rhizomys. It was subsequently transferred to the genus Brachyrhizomys (Flynn, 1982b) and later to Miorhizomys (Flynn, 2009). No additional material of M. harii has been found to date. 
Miorhizomys tetracharax (Flynn, 1982). This taxon was originally named as Brachyrhizomys tetracharax (Flynn, 1982a), but Flynn (2009) included it in Miorhizomys.The holotype of this species (YGSP 4810) consists of an associated palate with right and left I, M1-M3, right dentary fragment with i, m1-m3 and right half occiput with auditory region recorded from the Late Miocene (8.7 Myr) locality Y204 from the Dhok Pathan Formation in the Potwar Plateau, Pakistan (Flynn, 1982a). It is currently housed at the PMAE and it should be deposited eventually at the PMNH. More material of Miorhizomys tetracharax was found in the same formation at localities Y260 and Y388 (Flynn, 1982a), and more recently at Y631, Y952, and Y954. In India, Late Miocene remains of this species (Fig. 4E) were recorded from the Hari Scarp, Punjab (Flynn, 1982a), and from the "hominoid interval" of the Haritalyangar Scarp, Himachal Pradesh (Flynn et al., 1990). Finally, M. tetracharax was also found at the | Late Miocene vertebrate locality of Lufeng in southern China (Flynn and Qi, 1982).

Miorhizomys choristos (Flynn, 1982). The holotype of this species (YGSP 4053), an associated snout with both I1, left and right dentary fragments with broken i1, m1-m3, a distal left humerus, a proximal left ulna, a right femur portion and cranial fragments is housed at the PMAE and it should be eventually deposited at the PMNH (Flynn, 1982a). It comes from the Late Miocene (8.3 Myr) locality Y172, Dhok Pathan Formation, Potwar Plateau, Pakistan. At that time, the holotype was the sole material found of this taxon. Later on, additional specimens were recovered from Y457, Y535, and in northern India from the the "hominoid interval" of the Haritalyangar Scarp, Himachal Pradesh (Flynn et al., 1990).

Genus Eicooryctes Flynn, 1982. Type species: Eicooryctes kaulialensis Flynn, 1982

Eicooryctes kaulialensis Flynn, 1982. Flynn (1982a) named this taxon on the basis of some cranial and dentary fragments from the Late Miocene (8.0-7.2 Myr) localities Y434, Y437 and Y438 of the upper Dhok Pathan Formation, Kaulial Kas, Potwar Plateau, Pakistan. Its holotype, a palate and snout with broken incisors and left and right M1-M2 (YGSP 15320), is currently housed at the PMAE and it should eventually be 
returned to Pakistan where it would be deposited at the PMNH. Recently additional material of this species was been found at locality Y898.

Genus Protachyoryctes Hinton, 1933. Type species: Protachyoryctes tatroti Hinton, 1933

Protachyoryctes tatroti Hinton, 1933. This species was named by Hinton (1933) on the basis of a partial right mandible with m1-m3 (GSI D272), which is housed in the BMNH (paleontology collection). Hinton (1933) indicated that this material comes from a Pliocene horizon near Tatrot village, Salt Range, Pakistan. However, its provenance has been thrown into doubt since, in particular, the discovery of new material belonging to this taxon at the Late Miocene (7.8-7.1 Myr) localities Y434, Y909, and Y369 in the Dhok Pathan Formation of the Potwar Plateau, Pakistan (Flynn, 1982a). Flynn (1982a) pointed out the presence directly beneath Tatrot of much older rocks (more than $6 \mathrm{Myr}$ ), which he suspected was the provenance of the holotype of $P$. tatroti. These doubts are supported by the great resemblance between this species and the Late Miocene Tachyoryctes makooka.

Genus Rhizomyides Bohlin, 1946. Type species: Rhizomyides sivalensis (Lydekker, 1884)

Synonymy: Rhizomyoides Black, 1972

Referred species: Rhizomyides punjabiensis, $R$. carbonnelli, R. platytomeus, $R$. mirzadi

This genus was created by Bohlin (1946) to include the two Siwalik rhizomyines known by him at that time (R. sivalensis (Lydekker, 1884) and R. punjabiensis (Colbert 1933)), which were considered, in those days as belonging to the genus Rhizomys. Hinton (1933) had named four new species of "Rhizomys" from the Siwaliks (R. nagrii, R. pinjoricus, $R$. lydekkeri and $R$. pilgrimi), but this was apparently unknown to Bohlin. According to Bohlin (1946), R. sivalensis and R. punjabiensis were congeneric and clearly distinct from Rhizomys. Thus, he proposed the genus Rhizomyides and chose Rhizomyides sivalensis as the type species. Black (1972) in his review of the fossil rodents from the Siwaliks mistook this genus name as Rhizomyoides. This spelling error 
was repeated by subsequent authors (see e.g. Gupta et al., 1978; Vasishat et al., 1978; Brandy 1979a) until review by Flynn (1981).

Rhizomyides sivalensis (Lydekker, 1884). Lydekker (1878) briefly described two mandibular rami of a new rodent from Jabi, Punjab, Pakistan. Lydekker (1878) thought this material could probably represent a new species, but he cautiously proposed the name $R$. sivalensis and it turned out his thoughts were confirmed. As this new taxon was named with uncertainty it cannot be taken into account (article 67.2.5 of the Internationat-International Commission on Zoological Nomenclature, eøde of zoelogical nomenclature, 20001999: article 67.2.5) and it was Lydekker (1884) who made the name Rhizomys sivalensis available. Its holotype (GSI D97) is a left dentary fragment with i1, m2-m3 from Jabi. It is housed in the BMNH (paleontology collection). Additional material of this species has been recorded from the Potwar Plateau, Pakistan and from the Upper Siwaliks of the Siwalik Hills, India (Flynn, 1982a).

Rhizomyides carbonnelli (Brandy, 1979). Brandy (1979a) named this taxon Rhizomyoides carbonnelli repeating the spelling error made by Black in 1972 in the generic name Rhizomyides created by Bohlin in 1946 (see above). The holotype of this species (PEC 101) is a right mandible with i, m1-m3 from the Late Miocene-Early Pliocene of Pul-e Charkhi, Kabul, Afghanistan (Brandy, 1979a, 1979b, 1981). It is currently housed in the collections of the UM2 (B. Marandat, pers. comm. 2011).

Rhizomyides platytomeus Flynn, Heintz, Sen et Brunet, 1983. This species was named on the basis of a left dentary with i, m1-m3 (AFG 059) recorded from the middle Pliocene locality of Lataband, Sarobi Basin, Afghanistan (Flynn et al., 1983). It is currently housed in the paleontological collections of the MNHN (S. Sen, pers. comm. 2011). Unfortunately no additional material of this taxon has been found to date.

Rhizomyides mirzadi (Lang et Lavocat, 1968). Lang and Lavocat (1968) named the new species Rhizomys mirzadi on the basis of a right mandibular fragment with $\mathrm{m} 2$ (BAM 1) and Kanisamys bamiani based on an isolated m1 (BAM 2) from the Late Miocene Bamian Basin (Afghanistan). Brandy (1981) reallocated Rhizomys mirzadi to 
the genus Protachyoryctes. The reexamination of these two specimens and an unpublished third one (BAM 3), led Flynn (1983) to gather all them in a sole species, which he transferred to the genus Rhizomyides. Thus, Kanisamys bamiani is a synonym of Rhizomyides mirzadi. The holotype (BAM 1) is currently housed in the collections of the MNHN (S. Sen, pers. comm. 2011).

Rhizomyides punjabiensis (Colbert, 1933). Colbert (1933) described a small rhizomyine that he named Rhizomys punjabiensis. Bohlin (1946) coined the new genus Rhizomyides and allocated this species to it. R. punjabiensis was later reassigned to the genus Brachyrhizomys (Flynn 1981, 1982a, 1982b, 1984, 1985). Flynn (1986, 1990) later recognized the appropriate attribution Rhizomyides, making it the oldest known species of this genus. The holotype (AMNH 19762), a right mandibular ramus with the $\mathrm{m} 2$ and $\mathrm{m} 3$ and the posterior portion of the incisor, and only record of this species in those days, comes from the Late Miocene (Flynn, 1982a) Lower Siwalik beds of Bilaspur, Punjab, India (Colbert, 1933). Additional material of this species has been recorded from the early Late Miocene of Pakistan, near Kaulial and at the localities Y797, Y259 and Y450 from the Nagri Formation, Potwar Plateau (Flynn, 1982a)

Rhizomyides lydekkeri (Hinton, 1933) and Rhizomyides saketiensis (Gupta, Verma et Tewari, 1978). Rhizomyides lydekkeri was named by Hinton (1933) as Rhizomys lydekkeri. Its holotype (BMNH 15925) is a partial mandible with m1-m3 that comes from the Pliocene Upper Siwaliks of Northern India. Colbert (1935) considered this specimen together with some others (BMNH 15926, 15927 and 15927a) as Rhizomys sp. and pointed out that they probably did not belong to Rhizomys sivalensis because of their larger size and more recent age. However, Black (1972) synonymized the two species, and Flynn (1982b) considered them to represent the genus Rhizomyides.

Gupta et al., (1978) named the new species Rhizomyoides saketiensis on the basis of two dentary fragments from the Pliocene/Pleistocene Tatrot beds at Saketi Park (Himachal Pradesh). The holotype (GSI 19549) is a partial right mandibular ramus with $\mathrm{m} 2$ and m3. Flynn (1983) reallocated this species to the genus Rhizomyides. It is unknown if $R$. lydekkeri and R. saketiensis represent the same species (Flynn, 1982b; 
Flynn et al., 1983). Pending a re-examination of Hinton's (1933) original material, we have preferred not to notinclude these two taxa in our analysis.

Genus Kanisamys Wood, 1937. Type species: Kanisamys indicus Wood, 1937

Referred species: Kanisamys nagrii, K. sivalensis, K. potwarensis

In 1932, G. E. Lewis of Yale University collected some fossil rodents from the Siwalik deposits from the Chinji and Nagri zones of what was then North India, which he gave to A. E. Wood for study. Some of these specimens turned out to belong to a new genus that Wood (1937) named Kanisamys.

Kanisamys indicus Wood, 1937. The holotype of this species (YPM 13810), a right mandible with m1-m3, comes from the Chinji Zone, South south of Chinji Village, now Pakistan (Wood, 1937). Additional material of this taxon has been found in Pakistan from Middle Miocene localities in the Chinji Formation (Flynn et al., 1995). Furthermore, a fragmentary mandible (specimen D 271) from near Chinji (Attock District) considered by Hinton (1933) as Theridomys was reallocated to K. indicus by Black (1972). K. indicus has also been recorded from the locality 18 in the Chinji Formation at Daud Khel (Munthe, 1980), from the locality H-GSP 107 in the Chinji Formation, Banda Daud Shah (Wessels et al., 1982) and at various localities in the | Lower Manchar formation, Sind (Wessels and de Bruijn, 20032001).

Kanisamys sivalensis Wood, 1937. The holotype of this species (YPM 13801), a left mandible with m1-m3, comes from Lower Alternations, East of Haritalyangar, India (Wood, 1937). Additional material of this taxon has been recorded from various Late Miocene localities in the Upper Nagri and lower Dhok Pathan formations, Potwar Plateau, Pakistan (Jacobs 1978; Flynn, 1982a; Flynn et al., 1995).

Kanisamys nagrii Prasad, 1968. This species was named on the basis of a single left dentary fragment (GSI 18086) with i1M2-3 (Prasad, 1968), which was refigured by Flynn (1982b). It comes from the Late Miocene Lower Alternations, East of Haritalyangar, India. Additional material of this taxon has been recorded in the same 
area (Fig. 4A-C) as well as from the upper portion of the Chinji Formation, and the Late Miocene Nagri Formation, Potwar Plateau, Pakistan (Flynn, 1982a).

Kanisamys potwarensis Flynn, 1982. This species was named by Flynn (1982a) on the basis of various isolated molars (Fig. 4D). The holotype of this taxon (YGSP 8379), a left M3, comes from the Middle Miocene locality Y491 in the Chinji Formation, Potwar Plateau, Pakistan. Additional material of this taxon from the same area is now recognized at localities Y709, Y733, Y430, Y491, Y668, Y59, Y641, and Y651 and Y41 (14.3 to 13.4 Myr). Kanisamys cf. potwarensis has been mentioned from the Lower Siwalik Group of Ramnagar, Udhampur District, Jammu and Kashmir, India (Parmar and Prasad, 2006; Sehgal and Patnaik in press).

Genus Nakalimys Flynn et Sabatier, 1984. Type species. Nakalimys lavocati Flynn and Sabatier, 1984

Nakalimys lavocati Flynn et Sabatier, 1984. This taxon was named on the basis of a palate and mandible, two dentaries, an isolated lower incisor and some lower and upper molars from the early Late Miocene site of Nakali, Kenya (Flynn and Sabatier, 1984). The holotype (KNM-NA 7700) is a palate and mandible with left and right M1-M3 and i1 m1-m3. Nakalimys cf. lavocati has been found in the coeval site of Chorora, Ethiopia (Geraads, 1998).

Genus Pronakalimys Tong et Jaeger, 1993. Type species. Pronakalimys andrewsi Tong and Jaeger, 1993

Pronakalimys andrewsi Tong et Jaeger, 1993. This species was named on the basis of 13 partial lower jaws (7 with m1-m3, 5 with $\mathrm{m} 1-\mathrm{m} 2$ and 1 with $\mathrm{m} 3$ ) and a right maxilla with M1-M3 from the Middle Miocene site of Fort Ternan, Kenya (Tong and Jaeger 1993). The holotype (KNM-FT64-007) is a right maxilla. No additional material of this taxon has been found so far. 
Genus Prokanisamys de Bruijn, Hussain et Leinders, 1981. Type species:

Prokanisamys arifi de Bruijn, Hussain et Leinders, 1981

Referred species: Prokanisamys kowalskii, P. benjavuni, P. major, P. sp. Libya

Except for a few remains of Prokanisamys sp. described by Wessels et al., (2003) from the Lower Miocene of Libya, all the specimens of this genus found to date come from the Asian continent (Pakistan and Thailand).

Prokanisamys arifi de Bruijn, Hussain et Leinders, 1981. This species was defined on the basis of some isolated molars $(6 \mathrm{~m} 1,11 \mathrm{~m} 2,11 \mathrm{~m} 3,6 \mathrm{M} 1,6 \mathrm{M} 2$ and $16 \mathrm{M} 3)$ from the Lower Miocene H-GSP 116 locality of the Murree Formation, Banda Daud Shah, Kohät, Pakistan (de Bruijn et al., 1981). The holotype (specimen n²2) is a right $\mathrm{m} 1$ currently housed at the IVAU. Additional material of this species has been found at the localities Z126, Z122, Z120 and Z 124 of the Chitarwata and Vihowa Formations, Zinda Pir Dome, Pakistan, as well as at the localities H-GSP 81114a, H-GSP 8424, HGSP 81114, H-GSP 8426 (Sehwan Section) and H-GSP 8107a, H-GSP 8209, H-GSP 8311 and H-GSP 8106 (Gaj River Section) of the Lower Manchar Formation, Sind, | Pakistan (Wessels and de Bruijn 20032001; Lindsay et al., 2005; Wessels 2009).

Prokanisamys kowalskii (Lindsay, 1996). Lindsay (1996) coined a new species of Eumyarion as E. kowalskii on the basis of various molars and some isolated incisors recorded from the latest Oligocene (Lindsay et al., 2005; Flynn, 2009) locality Z113, Zinda Pir Dome, Pakistan. Wessels and de Bruijn (2001) transferred E. kowalskii to the genus Prokanisamys because of the greater closeness to the latter genus than to Eumyarion from Europe and Western Asia. The holotype of this species (PMNH $\mathrm{Z} 113 / 679)$ is a right isolated M1.

Prokanisamys benjavuni (Mein et Ginsburg, 1985). The preliminary results of a field campaign carried out in Li Mae Long, Lamphun district, Thailand by P. Mein and L. Ginsburg in 1984 in collaboration with the DMR and the University of Chiang Mai (Thailand) lead them to name a new species of rhizomyine: Kanisamys benjavuni (Mein and Ginsburg, 1985). Jacobs et al. (1989) reallocated this species to the genus Prokanisamys, a conclusion with which Mein and Ginsburg (1997) agreed after being 
able to sample more specimens of this taxon. Prokanisamys benjavuni comes from $\mathrm{Li}$, Lamphun district, Thailand. This locality was first considered as Early Miocene until the works of Chaimanee et al. (2007) proved it to be Middle Miocene in age. The holotype of this taxon ( $\mathrm{T} \mathrm{Li} \mathrm{203),} \mathrm{a} \mathrm{left} \mathrm{isolated} \mathrm{m} 3$ (the single complete $\mathrm{m} 3$ kown at the time), is housed at the collections of the FSL under the number FSL 67035 (Mein, pers. comm. 2011). Additional material of this species has also been found in the MaeMoh Basin, northern Thailand (Chaimanee et al., 2007) as well as in some Pakistani late Early Miocene levels (5, 6 and 6 bis) of Dera Bugti (Welcomme and Ginsburg, 1997; Welcomme et al., 2001) and at H-GSP 8114a, H-GSP 8114, H-GSP 8424 and H-GSP 8426 localities in the Lower Manchar Formation, Sehwan Section (Wessels and de Bruijn, 2001).

Prokanisamys major Wessels et de Bruijn, 2001. The holotype of this species (specimen $n^{\circ} 4522$ ) is an isolated left M1 from the Middle Miocene locality H-GSP 81.14 of the Lower Manchar Formation, Sind, Pakistan. It is currently housed at the IVAU. Additional material of this species has been found in the same area at late Early and Middle Miocene localities (H-GSP 8106, H-GSP 8227, H-GSP 8224, H-GSP 8424, H-GSP 8214, H-GSP 8425, H-GSP 8426, H-GSP 8427) as well as at some localities (YGSP 591, Y-GSP 592, Y-GSP 642, Y-GSP 501, Y-GSP 589, Y-GSP 491, Y-GSP 640, Y-GSP 641, Y-GSP 496, Y-GSP 634) of similar age on the Potwar Plateau, Pakistan (Flynn, 1986; Jacobs et al., 1990; Wessels and de Bruijn, 2001). The specimens from this latter area were first identified as Prokanisamys benjavuni (Flynn, 1986; Jacobs et al., 1990) until the discovery of the species Prokanisamys major (Wessels and de Bruijn, 2001).

Prokanisamys sp. Wessels, Fejfar, Peláez-Campomanes et de Bruijn, 2003. Two paleontological field campaigns carried out in 1983 and 1997 in various Miocene levels of the Marada Formation, Jebel Zelten, Libya, resulted in the discovery of some large and small mammals. Among the latter, five isolated teeth $(3 \mathrm{M} 1,1 \mathrm{~m} 2,1 \mathrm{~m} 3)$ of a species of Prokanisamys were found at the Early Miocene levels ATH4B, ATH5A1 and ATH7A2 (Wessels et al., 2003). This finding is of relevance not only as the only record 
of Prokanisamys found to date in Africa, but also for being the oldest record of a rhizomyine found in this continent.

\section{Phylogenetic analysis}

\section{Previous work}

Flynn (1990). The first attempt at deciphering the relationships of the extinct and extant Rhizomyinae (Rhizomyidae sensu Flynn, 1982a) based on the synapomorphies of the different genera of rhizomyines (a group then at the family level) was carried out by Flynn (1990). According to the hand-generated cladogram (Fig. 6), the Asian Prokanisamys was the most basal genus of the ingroup, followed by the East African Nakalimys. The analysis supported the monophyly of (Kanisamys, Protachyoryctes, Eicooryctes, Tachyoryctes), which Flynn (1990) considered as the subfamily Tachyoryctinae. In addition, the clade ("Brachyrhizomys", Rhizomys, Cannomys) would constitute the subfamily Rhizomyinae. Flynn (1990) inferred two plausible relationships for the sister genus of Kanisamys, Rhizomyides: either it belongs to the Tachyoryctinae or it is the sister taxon to the clade constituted by the Tachyoryctinae and Rhizomyinae.

\section{New analysis}

32 most parsimonious trees were generated with a length of 158 and a relatively high degree of homoplasy $(\mathrm{CI}=0.456$ and $\mathrm{RI}=0.819)$. The strict and semi-strict consensus trees are identical and largely resolved (Fig. 7A) with five polytomies each. In the majority-rule consensus tree one of these polytomies disappears and one, although persisting, involves a reduced number of taxa (Fig. 7B). Bremer and relative Bremer support indices (Goloboff and Farris, 2001; Goloboff et al., 2003) for each node are indicated on the cladogram in the figure 7A.

The transformations supporting the topology of this tree (under the ACCTRAN and DELTRAN optimizations) are listed in Table $1 \underline{2}$. Each internal node is discussed below, beginning from the most basal (whenever both unambiguous and ambiguous synapomorphies support a given node, only the former are mentionned). 
Node 62. Prokanisamys spp. + more derived taxa. This node is based on a single non-exclusive synapomorphy under ACCTRAN: mesolophid on the $\mathrm{m} 2$ short and wellseparated from the hypolophid.

Node 61. Prokanisamys spp. This clade is sustained by two exclusive and unambiguous synapomorphies, i.e weak lophodonty and mesolophid on the $\mathrm{m} 3$ short and well-separated from the hypolophid, and two non-exclusive and unambiguous synapomorphies, i.e. mesolophid on the $\mathrm{m} 1$ short and well-separated from the hypolophid (a convergence with Nakalimys lavocati, the node 53 and some individuals of Miorhizomys nagrii and M. choristos) and anterosinus on M3 enclosed by anteroloph and paracone (a convergence with node 58).

Node 60. Pronakalimys andrewsi + more derived taxa. This node is supported by one exclusive and unambiguous synapomorphy, i.e. ectoloph on M2 absent, and one nonexclusive and unambiguous synapomorphy, i.e. ectoloph on M1 absent (a convergence with Prokanisamys kowalskii).

Node 59. Nakalimys lavocati + more derived taxa. One exclusive and unambiguous synapomorphy supports this node, i.e. anteroconid on $\mathrm{m} 1$ absent, as well as one nonexclusive and unambiguous synapomorphy, i.e. $\mathrm{m} 3$ enlarged (a convergence with Prokanisamys major).

Node 58. (Kanisamys potwarensis, $K$. indicus) + more derived taxa. This node is supported by two exclusive and unambiguous synapomorphies, i.e. labial anterolophid on $\mathrm{m} 1$ absent and mesoloph on M2 long and complete. It is also sustained by three nonexclusive and unambiguous synapomorphies, i.e. moderate hypsodonty (a convergence with Prokanisamys benjavuni, Tachyoryctes pliocaenicus and T. konjiti), presence of mesostyle on M1 (a convergence with Rhizomyides punjabiensis and Miorhizomys nagrii) and anterosinus enclosed by anteroloph and paracone on M3 (convergence with node 61).

Node 57. Kanisamys potwarensis $+K$. indicus. One non-exclusive and unambiguous synapomorphy supports this clade, i.e. mesolophid long and complete and separated from the hypolophid on $\mathrm{m} 2$ (a reversal).

Node 56. Kanisamys nagrii + more derived taxa. This node is supported by five exclusive and unambiguous synapomorphies: high lophodonty, labial anterolophid absent on $\mathrm{m} 2$ and $\mathrm{m} 3$, protosinusid absent on the $\mathrm{m} 2$ and $\mathrm{m} 3$. Two additional non- 
exclusive and unambiguous synapomorphies are present, i.e. posterior protoconidmetaconid connection absent on $\mathrm{m} 1$ (a convergence with some individuals of Kanisamys indicus and node 44) and mesolophid short and migrated toward the hypolophid on m3 (a convergence with Pronakalimys andrewsi).

Node 55. Kanisamys sivalensis+ more derived taxa. Two non-exclusive and unambiguous synapomorphies support this node, i.e. metaloph fused with posteroloph on M1 (a convergence with Kanisamys potwarensis) and posterosinus absent on the M1 (a convergence with Kanisamys potwarensis).

Node 54. Miorhizomys micrus $+($ Rhizomyides mirzadi, R. punjabensis $)+$ (Tachyoryctes makooka, Protachyoryctes tatroti) $+(R$. carbonnelli $(R$. platytomeus, $R$. sivalensis) ) + more derived taxa. This node is supported by five exclusive and unambiguous synapomorphies, i.e. dentary depth moderate, mesostyle on M1 absent, anterocone fused with anteroloph on M1, metaloph early fused with posteroloph on M2 and posterosinus absent on $\mathrm{M} 2$.

Node 53. Rhizomyides mirzadi $+R$. punjabensis. Two non-exclusive and unambiguous synapomorphies support this node, i.e. masseteric crest with short anterior extension (Prokanisamys major and maybe other species of this genus, Miorhizomys micrus, M. nagrii, M. harii, Eicooryctes kaulialensis and Cannomys badius) and mesolophid short and well-separated from the hypolophid on $\mathrm{m} 1$ (a convergence with node 61, Nakalimys lavocati, Kanisamys potwarensis and some specimens of Miorhizomys nagrii and M. choristos).

Node 52. Rhizomyides carbonnelli $+($. platytomeus, $R$. sivalensis $)$. This node is supported by two non-exclusive and unambiguous synapomorphies, i.e. lower masseteric crest inflated under m2 (a convergence with Protachyoryctes tatroti and node 45) and presence of posterior protoconid-metaconid connection on m1 (a highly homoplastic character).

Node 51. Rhizomyides platytomeus $+R$. sivalensis. Two non-exclusive and unambiguous synapomorphies support this node, i.e. length of $\mathrm{m} 2$ between 4.5 and 5.5 mm (a convergence with some individuals of Miorhizomys choristos, M. tetracharax 
and node 48) and mesolophid long and complete and separated from the hypolophid on $\mathrm{m} 2$ (a reversal).

Node 50. Protachyoryctes tatroti + Tachyoryctes makooka. This node is supported two non-exclusive and unambiguous synapomorphies, i.e. mesolophid short and migrated toward the hypolophid (a convergence with some specimens of Kanisamys nagrii, K. sivalensis, Eicooryctes kaulialensis and Tachyoryctes pliocaenicus) and mure on the $\mathrm{m} 2$ constricted (an homoplastic character that is also found in Rhizomyides platytomeus, Miorhizomys harii, M. tetracharax, Rhizomys (Brachyrhizomys) shajius and Eicooryctes kaulialensis).

Node 49. Miorhizomys choristos + M. tetracharax + M: harii + M. blacki + M. nagrii + Rhizomys (Brachyrhizomys) shajius + more derived taxa. This node is supported by no less than four exclusive and unambiguous synapomorphies, i.e. masseteric crest without anterior extension, M1 hypselodont and M2 and M3 absent, and six non-exclusive and unambiguous synapomorphies, i.e. longitudinal ornamentation on i absent (a convergence with Miorhizomys micrus), mure on $\mathrm{m} 1$ constricted (a convergence with Tachyoryctes makooka), mesolophid long and complete and separated from hypolophid on $\mathrm{m} 2$ (a reversal), posterosinusid small on m3 (a convergence with Miorhizomys micrus, some individuals of M. pilgrimi and Tachyoryctes pliocaenicus), anterosinusid absent on $\mathrm{m} 3$ (a convergence with some specimens of Kanisamys nagrii and either with the node 52 or, as a parallelism, with Rhizomyides platytomeus and R. carbonnelli) and protosinus absent on M1 (a convergence with Prokanisamys benjavuni and some individuals of Rhizomyides punjabiensis).

Node 48. Rhizomys sinensis + Tachyoryctes splendens + all the descendants of their common ancestor (crown group). This clade is sustained by only one exclusive and unambiguous synapomorphy, i.e. posterior lake absent on M3, but four non-exclusive and unambiguous synapomorphies, i.e. $\mathrm{m} 2$ length between $4.5 \mathrm{~mm}$ and $5.5 \mathrm{~mm}$ (a convergence with node 51 and some individuals of Miorhizomys choristos and $M$. tetracharax), mure on $\mathrm{m} 3$ absent (a convergence with Miorhizomys choristos and $M$. tetracharax), posterosinusid on m3 absent (a convergence with Miorhizomys choristos and M. tetracharax) and mesoloph long and complete on M3 (a reversal). 
Node 47. Anepsirhizomys opdykei + more derived taxa. Two non-exclusive and unambiguous synapomorphies support this node, i.e. high hypsodonty (a convergence with node 41) and posterior protoconid-metaconid connection on $\mathrm{ml}$ absent (a highly homoplastic character).

Node 46. Anepsirhizomys pinjoricus + more derived taxa. A single exclusive and unambiguous synapomorphy supports this node, i.e. masseteric crest with long anterior extension.

Node 45. Eicooryctes kaulialensis + more derived taxa. This node is supported by two exclusive and unambiguous synapomorphies, i.e. $\mathrm{m} 2$ length between $2.5 \mathrm{~mm}$ and $3.5 \mathrm{~mm}$ and mesolophid on $\mathrm{m} 2$ absent.

Node 44. Tachyoryctes pliocaenicus $+T$. konjiti $+T$. macrocephalus $+T$. splendens. Three non-exclusive and unambiguous synapomorphies support this node, i.e. mure on $\mathrm{m} 1$ absent (a convergence with node 42), posterior protoconid-metaconid connection on $\mathrm{m} 1$ absent (a highly homoplastic character) and anterosinusid on $\mathrm{m} 1$ present (a reversal).

Node 43. Miorhizomys pilgrimi + more derived taxa. This clade is sustained by only one non-exclusive and unambiguous synapomorphy, i.e. mesolophid on $\mathrm{m} 2$ that is a long continuation of the protoconid (a convergence with Miorhizomys choristos).

Node 42. Rhizomys (Brachyrhizomys) shansius + more derived taxa. This node is supported by three exclusive and unambiguous synapomorphies, i.e. deep dentary, infraorbital foramen without ventral slit and hypolophid on $\mathrm{m} 2$ isolated, and one nonexclusive and unambiguous synapomorphy, i.e. anterosinusid on $\mathrm{m} 2$ absent (a reversal).

Node 41. Cannomys badius + more derived taxa. This node is supported by one exclusive and unambiguous synapomorphy, i.e. mesolophid on $\mathrm{m} 1$ that is a long continuation of the protoconid, and two non-exclusive and unambiguous synapomorphies, high hypsodonty (a convergence with node 47) and entoconid on m3 isolated (a convergence with Miorhizomys choristos and M. tetracharax).

Node 40. Rhizomys pruinosus $+R$. sinensis $+R$. sumatrensis. This node is supported by two exclusive and unambiguous synapomorphies, i.e. mesoloph on M1 and M3 long and complete but divided, in early wear, with a buccal cusp, and one non-exclusive and unambiguous synapomorphy, i.e. mesoloph on M2 long and complete but divided, in early wear, with a buccal cusp (a convergence with Miorhizomys choristos). 


\title{
Discussion
}

\author{
Prokanisamys \\ Prokanisamys is the oldest known genus of the rhizomyines. The results of this work \\ support the monophyly of this taxon. They do not confirm the position of that the most \\ ancient species of the genus, P. kowalskii, ias the most basal one within this clade. Even \\ though this Late Oligocene species shows the first phase of the rhizomyine dentition, its \\ lophodonty is incipient and its hypsodonty is hardly greater than that of typical muroids. \\ We- therefore- hypothesize that further work will eventually resolve $P$. kowalskii as the \\ most basal member of the genus.
}

\section{The African Pronakalimys and Nakalimys}

Pronakalimys and Nakalimys branch sequentially between Prokanisamys and Kanisamys. Pronakalimys and Nakalimys are indeed much closer morphologically to Early and Middle Miocene Asian fossil rhizomyines than to the African Tachyoryctes. The occurrence of Prokanisamys sp. from the Early Miocene of Jebel Zelten (Fejfar and Horáček 2006; Wessels et al., 2003, 2008) provides evidence of an Early Miocene migration of rhizomyines from Asia to Africa. However, the topology of our tree | suggests that the latter taxon Prokanisamys sp. did not give rise directly to Pronakalimys, which would be the fruit of a second immigration of rhizomyines into Africa. As suggested by Flynn and Sabatier (1984), Nakalimys lavocati is more basal than Kanisamys indicus and not directly ancestral to Tachyoryctes.

\section{Kanisamys}

Wessels and de Bruijn (2001) pointed out that ancestor-descendent relationships within this genus were not clear. In fact, the genus Kanisamys is not monophyletic according to our results. However, $K$. indicus and $K$. potwarensis do form a clade and are, therefore, true Kanisamys. In contrast, "K." nagrii and "K." sivalensis insert sequentially on the stem leading to more derived rhizomyines. Flynn (1982a, 1984, 1986) was, therefore, correct in considering $K$. potwarensis most closely related to $K$. 
indicus than to other species then considered as belonging to Kanisamys. His opinion that " $K$ ". nagrii is more basal than " $K$ ". sivalensis and that the former is closer to the latter than to either K. indicus or K. potwarensis is confirmed. Flynn (1982a, 1984, $1986)$ also suggested that " $K$ ". nagrii and " $K$ ". sivalensis are more derived than $K$. indicus and K. potwarensis, which is substantiated by our results. However, the suggestion that $K$. indicus would be a direct ancestor of “ $K$ ". sivalensis (Black, 1972; Flynn 1982a) is not supported.

\section{Protachyoryctes}

The sister species Protachyoryctes tatroti and "Tachyoryctes" makooka are both hypsodont, have reduced but distinct mesolophids and have retained the protosinus on the M1. This latter trait is distinctive of the most basal genera of the subfamily like Prokanisamys, Kanisamys, Pronakalimys, Nakalimys and Rhizomyides (see Flynn 1982a). It becomes less marked in P. tatroti and "T." makooka (in which the protosinus is shallow). The topology of our cladogram implies that " $T$." makooka should be reallocated to the genus Protachyoryctes (Fig. 7) as already hypothesized by LópezAntoñanzas and Wesselmann (in press). From these results a unidirectional dispersal event from southern Asia to Africa at the origin of "T." makooka can be inferred between 6 and 8 Myr (Figs. 8 and 9). Contrary to the suggestion of Black (1972), and what its name may suggest, Protachyoryctes is not closer to Tachyoryctes (sensu stricto) than to Rhizomys.

\section{Rhizomyides}

As currently understood, Rhizomyides is a paraphyletic taxon. True Rhizomyides, with $R$. sivalensis as type, constitute the sister group of Protachyoryctes according to the majority-rule consensus tree (Fig. 7B).

As Flynn (1982a, 1986, 1990) pointed out, Rhizomyides and Kanisamys share many traits (e.g., similar degree of hypsodonty, inclined masseteric crest, a strongly rounded I1, a large posterior enamel lake on M3). This fact led Flynn $(1983,1986)$ to think that the origin of Rhizomyides could have been earlier than reflected by its first occurence in the fossil record and that it could have evolved from an early Kanisamys. This is not fully supported by our results. The fact that Rhizomyides sivalensis retained a strong 
mesolophid on the M2 (usually reduced in K. sivalensis) led Flynn (1982a) to suggest that $R$. sivalensis may have evolved from Kanisamys outside Pakistan and later immigrated to the Potwar Plateau. This hypothesis is congruent with our results given that the species most closely related to $R$. sivalensis ( $R$. carbonnelli and $R$. platytomeus) were both found in Afghanistan_Brandy, 1979a, 1979b, 1981; Flynn et al., 1983). In the Late Miocene a form close to $R$. carbonnelli would have evolved there to give rise to the lineages of $R$. platytomeus and $R$. sivalensis the latter taxon subsequently immigrating to the Potwar Plateau (Fig. 8). We agree with the suggestion of Flynn (1983) and Flynn et al. (1983) according to which there is probably neither direct relationship between $R$. carbonnelli and $R$. sivalensis nor between $R$. platytomeus and Tachyoryctes.

\section{"Rhizomyides" mirzadi and "R". punjabiensis}

The generic attribution of "Rhizomyides" mirzadi and " $R$ ". punjabiensis has been controversial. " $R$ ". mirzadi has been considered as belonging to Kanisamys (Jacobs, 1978), Protachyoryctes (Brandy, 1981) and Rhizomyides (Flynn, 1983). " $R$ ". punjabiensis was considered Rhizomyides by Bohlin, (1946), reassigned to Brachyrhizomys by Flynn (1982a) and returned to Rhizomyides by Flynn $(1986,1990)$. Our results suggest that a new genus name is required for these two taxa, which are sister species (Fig. 8).

\section{Miorhizomys}

Another interesting result of the present work is that the genus Miorhizomys does not appear monophyletic. Flynn (1982a) suggested that M. micrus is a conservative descendant of the "Rhizomyides" punjabiensis lineage. This hypothesis is not greatly different from the topology suggested by our tree, and M. micrus is the most basal species of Miorhizomys as currently understood. Interestingly enough, Rhizomys (Brachyrhizomys) shajius nests within the various species of Miorhizomys, and does not appear closely related to $R$. (B.) shansius. This is not very surprising because the former species is primitive in molar narrowness, low hypsodonty and retention of a mure, and short mesolophid on the m3), and is represented by only one jaw (Flynn 1993). Note 
that $R$. (B.) shajius, while older (5.9 Myr vs 4-3.3 Myr, see Flynn, 2009), it occurs in the same basin as $R$. (B.) shansius.

The majority-rule consensus tree does not solve the interrelationships between Miorhizomys blacki, M. nagrii and Rhizomys (Brachyrhizomys) shajius (Fig. 7B). Nevertheless, it shows that $M$. tetracharax, M. choristos and M. harii form a monophyletic group of which $M$. choristos is the most basal species and in which $M$. tetracharax and M. harii are sister taxa. However, in the strict consensus tree (Fig. 7A), the interrelationships between M. choristos, M. tetracharax, M. harii, M. blacki, M. nagrii and Rhizomys (Brachyrhizomys) shajius remain unsolved. The number of true Miorhizomys species remains therefore unsettled. M. micrus, M. blacki, M. nagrii and R. (B.) shajius show some burrower adaptations. An increase of specialization toward a fossorial way of life is shown in the more derived M. tetracharax, M. choristos and M. harii, a trend continued by the most derived species of the subfamily.

\section{The crown group}

Another interesting result is the evidence of two important lineages originating from the basal node of the crown group (48). One corresponds to all taxa originating from node 47 (Anepsirhizomys opdykei + more derived taxa). This clade is characterized by the synapomorphies of having high hypsodonty and lacking posterior protoconidmetaconid connection on the $\mathrm{m} 1$. We understand this clade as the tribe Tachyoryctini

and we provide it with the following phylogeneticat definition: The most inclusive clade containing Tachyoryctes splendens (Rüppell 1836) but not Rhizomys sinensis Gray, 1831. The other lineage originates from node 43 (Miorhizomys pilgrimi + more derived taxa). It is characterized by the synapomorphy of having the mesolophid on the $\mathrm{m} 2$ as a long continuation of the protoconid. This clade is the tribe Rhizomyini, whose phylogenetic definition is: The most inclusive clade containing Rhizomys sinensis Gray, 1831 but not Tachyoryctes splendens (Rüppell 1836).

The divergence between the tribes Tachyoryctini and Rhizomyini can be estimated as having occurred about 10 Myr (Fig. 8), because the oldest record of Miorhizomys pilgrimi is near $9.5 \mathrm{Myr}$. 
Tribe Tachyoryctini. This tribe is constituted by Anepsirhizomys opdykei and more derived taxa. Our work sheds light on the controversial taxonomic position of Anepsirhizomys. This genus of unclear affinity has been considered a rhizomyine as well as a tachyoryctine (Flynn et al., 1990). According to the results of our analysis, Anepsirhizomys is the most basal genus within the tribe Tachyoryctini. The reallocation of "Rhizomys" pinjoricus to Anepsirhizomys as suggested by Flynn et al. (1990) and Flynn (2009) is not supported by this work. Anepsirhizomys pinjoricus is actually more derived and should be reallocated into a genus of its own.

The African Tachyoryctini (T. pliocaenicus and more derived species) would come from an immigration of a species close to Eicooryctes kaulialensis in Africa. This is in agreement with the fact that Eicooryctes displays many derived characters shared by and even, for some of them, accentuated in the more modern species of Tachyoryctes (e.g., hypsodonty, absence of mesolophid on the $\mathrm{m} 2$ and $\mathrm{m} 3$, lack of protosinus on the M1).

Tribe Rhizomyini. This clade is constituted by Miorhizomys pilgrimi plus more derived taxa. The origin of the Rhizomyini is to be found at the beginning of the Late Miocene in a Miorhizomy -like form. According to our consensus trees, the most basal taxon of this clade is Miorhizomys pilgrimi.

After studying Brachyrhizomys shansius, Flynn (2009) concluded that this taxon should be treated as a subgenus of Rhizomys (see above). For this reallocation to be accepted, the genus Cannomys would have to be synonymized with Rhizomys. However, the former differs from the latter in its smaller size and in having proodont incisors and smooth sole pads (Nowak, 1999). Therefore, we favor the restablishment of the genus Brachyrhizomys. Cannomys is the sister-group of Rhizomys.

\section{Conclusion}

The most basal representatives of the subfamily Rhizomyinae belongs to Prokanisamys. The oldest species of this genus is $P$. kowalskii from the Late Oligocene of Pakistan. This record is followed in age by $P$. arifi and P. major from Pakistan. These two species persisted into the Middle Miocene of Pakistan, where they were 
sympatric with Kanisamys indicus. In Thailand, P. benjavuni is recorded in the Middle Miocene. During Late Miocene times, the rhizomyines experienced their greatest diversification with 14 species distributed across five genera (Kanisamys, Rhizomyides, Protachyoryctes, Eicooryctes and Miorhizomys) in Pakistan, India and China. Our results call the monophyly of several of these genera into question. The Asian Pliocene rhizomyine record suggests that the diversity of these animals dropped there at this time. In fact, they are only represented by four species belonging to four genera (Rhizomyides, Brachyrhizomys, Anepsirhizomys and a still unamed genus for "A." pinjoricus), which occurred in Afghanistan, Pakistan, India and China.

African fossil Rhizomyinae are scarce; the oldest and sole Early Miocene representative is Prokanisamys sp. from Jebel Zelten (Libya). This recent discovery provides evidence of an Early Miocene migration of members of this family between Asia and Africa through the "Gomphotherium landbridge". In Africa, a single species of rhizomyine is known from the Middle Miocene (Pronakalimys andrewsi from Fort Ternan, Kenya), two from the Late Miocene (Nakalimys lavocati from Nakali, Kenya, and the recently discovered Protachyoryctes makooka from the Middle Awash, Ethiopia). From the Pliocene Hadar Formation (Afar, Ethiopia) a single species of Tachyoryctes is known (T. pliocenicus). The most recent fossil species of Tachyoryctes known to date is T. konjiti, which comes from the Pleistocene of Melka-Kunturé (Ethiopia).

Together with other rodents such as the Ctenodactylidae (López-Antoñanzas and Knoll, 2011), Diatomyidae (López-Antoñanzas, 2011), basal Mureideaae (LópezAntoñanzas, 2009), Zapodidae (López-Antoñanzas and Sen, 2006) and Thryonomyidae (López-Antoñanzas et al., 2004), the rhizomyines provide a fine example of long distance dispersal of rodents consistent with geological evidence, indicating the establishment of an Early Miocene corridor between Afro-Arabia and Eurasia. Rhizomyines survive in Asia and Africa, and their phylogenetic relationships imply the ancestry to be found in Asia. This subfamily underwent a wide geographic expansion during Miocene times. From a morphological viewpoint African fossil rhizomyines appear close to the Asian ones, and the extant African rhizomyines share more synapomorphies with certain Pakistani Late Miocene species than with the older African taxa. The hypothesis that this subfamily dispersed more than once from Asia 
into Africa could explain those facts and is supported by our results. A firstinitial geodispersal of Prokanisamys from Pakistan to East Africa would have taken place at the beginning of the Early Miocene. From this first event Prokanisamys sp. from Jebel Zelten would have originated. The second and third dispersalist events may have taken place not earlier than $18 \mathrm{Myr}$ and would have given rise to the Middle Miocene Pronakalimys and to the Late Miocene Nakalimys (Fig. 9). The hypothesis that African Nakalimys could have originated from the dispersal into Africa of an Asian Kanisamys by Middle Miocene times is not supported by our results.

With respect to the Late Miocene Protachyoryctes makooka and the African Tachyoryctini, two unidirectional dispersal events from southern Asia to Africa took place in Late Miocene times (not earlier that 8.2 Myr). The first one would have been at the origin of Protachyoryctes makooka, whereas the derivation of the African Tachyoryctini (Tachyoryctes spp.) would have come from an independent entery of this group into Africa (Fig. 9).

\section{Acknowledgements}

We sincerely thank C. Denys (Muséum National d'Histoire Naturelle, Paris), F. Mayer and N. Lange (Museum für Naturkunde der Humboldt-Universität, Berlin), G. Rößner (Staatssamlung für Paläontologie und Geologie, Munich), P. Holroyd (University of California, Berkeley), J. Galkin, J. Meng, R. O’Leary and C. Mehling (American Museum of Natural History, New York) for having made available the rhizomyine material under their care. D. Brandy (Neuville sur Touques), H. de Bruijn (Utrecht University, Utrecht), P. Jenkins (The Natural History Museum, London), B. Marandat and L. Marivaux (Université Montpellier II, Montpellier), P. Mein (Université Claude Bernard, Lyon I, Villeurbanne), S. Sen (Muséum national d'Histoire naturelle, Paris), P. Shepherd (British Geological Survey, Nottinghamshire), J. Thomas and E. Fara (Université de Bourgogne, Dijon) answered all our inquiries. W. Wessels (Utrecht University, Utrecht) kindly allowed us to use the photos of Prokanisamys arifi in our figure 1. M. R. Dawson (Carnegie Museum of Natural History, Pittsburgh) and an anonymous reviewer enhanced this work through careful, critical reading. The sojourns in Munich (RLA and FK) and Paris (RLA) were funded by the Alexander von 
Humboldt Foundation through sponsorships of renewed research stays in Germany and by the EDIT Gender Action Plan, respectively. This research received support from the SYNTHESYS Project (http://www.synthesys.info/), which is financed by European Community Research Infrastructure Action under the FP7 "Capacities" Program. RLA and FK are currently supported by the Ramón y Cajal Program and the research projects CGL2011-24829 and CGL2009-12143, respectively, of which they are PI.

\section{References}

Alemseged, Z., Geraads, D. 2000. A new Middle Pleistocene fauna from the BusidimaTelalak region of the Afar, Ethiopia. C.R. Acad. Sci., Earth and Planetary Sciences 331, 549-556.

Allen, G. M. 1939. A checklist of African mammals. Bull. Mus. Comp. Zool. Harvard Univ. 83, 1-763.

Beolchini, F., Corti, M. 2004. The taxonomy of the genus Tachyoryctes: a geometric morphometric approach. Ital. J. of Zool. 71, 35-43.

Black, C. C. 1972. Review of fossil rodents from the Neogene Siwalik Beds of India and Pakistan. Palaeontology 15, 238-266.

Blyth, E. 1851. Notice of a collection of Mammalia, Birds, and Reptiles, procured at or near the station of Chérra Punji in the Khásia hills, north of Sylhet. J. Asiat. Soc. Bengal 20, 517-524.

Bohlin, B. 1946. The fossil mammals from the Tertiary deposits of Taben-Baluk, Western Kansu, Part II: Simplicidentata, Carnivora, Artiodactyla, Perissodactyla, and Primates. Palaeontol. Sinica C 8b, 1-259.

Brandy, L.D. 1979a. Rongeurs nouveaux du Néogène d'Afghanistan. C.R. Acad. Sci., Série D 289, 81-83.

Brandy, L.D. 1979b. Etude de rongeurs muroides du néogène supérieur et du quaternaire d'Europe, d'Afrique du nord et d'Afghanistan: évolution, biogéographie, correlations. PhD thesis: Université des Sciences et Techniques du Languedoc.

Brandy, L.D. 1981. Rongeurs muroïdés de Néogène supérieur d'Afghanistan : évolution, biogéographie, corrélations. Paleovertebrata 11, 133-179.

Bremer, K. 1994. Branch support and tree stability. Cladistics 10, 295-304. 
Bucher, J. E. 1982. Family Rhizomyidae. In: Honacki, J., Kinmam, K. E., Koeppl, J. W. (Eds.), Mammals Species of the World, First Edition. Lawrence: Association of Systematics Collections, pp. 477-478.

Chaimanee, Y., Yamee, C., Marandat, B., Jaeger, J. J. 2007. First Middle Miocene Rodents from the Mae Moh Basin (Thailand): Biochronological and Paleoenvironmental Implications. Bull. Carnegie Mus. 39, 157-163.

Colbert, E. H. 1933. Two new rodents from the Lower Siwalik beds of India. Am. Mus. Novit. 633, 1-6.

Colbert, E. H. 1935. Siwalik Mammals in the American Museum of Natural History. Trans. Am. Phil. Soc. New Series 26, 1-401.

Colbert, E. H., Hooijer, D. A. 1953. Pleistocene mammals from the limestone fissures of Szechwan, China. Bull. Am. Mus. Nat. Hist. 102, 1-134.

Corbet, G. B., Hill, J. E. 1991. A World List of Mammalian Species, Third edition. Oxford University Press, Oxford.

De Bruijn, H., Hussain, S. T., Leinders, J. M. 1981. Fossil rodents from the Murree formation near Banda Daud Shah, Kohat, Pakistan. Proc. Kon. nederl. Akad. Wetensch. B 84, 71-99.

Ellerman, J.R. 1940. The families and genera of living rodents. Volume I. Rodents other than Muridae. London: British Museum (Natural History).

Ellerman, J.R. 1941. The families and genera of living rodents. Volume II. Family Muridae. London: British Museum (Natural History).

Ellerman, J. R., Morrison-Scott, T. C. S. 1951. Checklist of Palaearctic and Indian Mammals, 1758 to 1946, First Edition. British Museum (Natural History), London.

Ellerman, J. R., Morrison-Scott, T. C. S. 1966. Checklist of Palaearctic and Indian Mammals, 1758 to 1946, Second Edition. British Museum (Natural History), London.

Endo, H., Satoh, K., Cuisin, J., Stafford, B., Kimura, J. 2001. Morphological adaptation of the masticatory muscles and related apparatus in Asian and African Rhizomyinae species. Mammal Study 26, 101-108.

Fejfar, O., Horáček, I. 2006. The Early Miocene mammalian assemblages in Jebel Zelten, Libya. Lynx 37, 95-105. 
Flynn, L. J. 1981. Biostratigraphy and systematics of Siwalik Rhizomyidae (Rodentia). Unpublished PhD dissertation, University of Arizona, Tucson.

Flynn, L. J. 1982a. Systematic revision of Siwalik Rhizomyidae (Rodentia). Geobios $15,327-389$.

Flynn, L. J. 1982b. A revision of fossil rhizomyid rodents from northern India and their correlation to a rhizomyid biochronology of Pakistan. Geobios 15, 583-588.

Flynn, L. J. 1983. Sur l'âge de la faune de Vertébrés du bassin de Bamian, Afghanistan. C.R. Acad. Sci., Série II 297, 687-690.

Flynn, L. J. 1984. Mosaic evolution in a family of fossorial rodents. In: Buffetaut, E., Mazin, J. M., Salmon, E. (Eds.), Actes du Symposium paléontologique Georges Cuvier. Montbéliard: Ville de Montbéliard. pp. 185-195.

Flynn, L. J. 1985. Evolutionary patterns and rates in Siwalik Rhizomyidae (Rodentia). Acta Zool. Fenn. 170, 141-144.

Flynn, L. J. 1986. Species longevity, stasis, and stairsteps in rhizomyid rodents. Univ. Wyoming Contr. Geol, Spec. Pap. 3, 273-285.

Flynn, L. J. 1990. The natural history of rhizomyid rodents. In: Nevo, E., Reig, O. A. (Eds.), Evolution of Subterranean Mammals at the Organismal and Molecular Levels. A. R. Liss, New York. pp. 155-183.

Flynn, L. J. 1993. A new bamboo rat from the Late Miocene of Yushe Basin. Vert. Palasiatica 31, 95-101.

Flynn, L. J. 2009. The Antiquity of Rhizomys and Independent Acquisition of Fossorial Traits in Subterranean Muroids. Bull. Am. Mus. Nat. Hist. 331, 128-156.

Flynn, L. J., Barry J. C., Morgan M. E., Pilbeam D., Jacobs L. L., Lindsay E. H. 1995. Neogene Siwalik mammalian lineages: Species longevities, rates of change, and modes of speciation. Palaeogeogr. Palaeocl. Palaeoeco.115, 149-264.

Flynn, L. J., Heintz, E., Sen, S., Brunet, M. 1983. A new Pliocene tachyoryctine (Rhizomyidae, Rodentia) from Lataband, Sarobi Basin, Afghanistan. Proc. Kon. nederl. Akad. Wetensch. B 86, 61-68.

Flynn, L. J., Qi, G. 1982. Age of the Lufeng, China, hominoid locality. Nature 298, 746-747.

Flynn, L. J., Sabatier, M. 1984. A Muroid Rodent of Asian affinity from the Miocene of Kenya. Journal of Vertebrate Paleontology 3, 160-165. 
Flynn, L. J., Sahni, A., Jaeger, J. J., Singh, B., Bhatia, S. B. 1990. Additional fossil rodents from the Siwalik Beds of India. Proc. Kon. nederl. Akad. Wetensch. 93, $7-$ 20.

Gallotti, R., Collina, C., Raynal, J. P., Kieffer, G., Geraads, D., Piperno, M. 2010. The Early Middle Pleistocene Site of Gombore II (Melka Kunture, Upper Awash, Ethiopia) and the Issue of Acheulean Bifacial Shaping Strategies. Afr. Archaeol. Rev. 27, 291-322.

Geraads, D. 1998. Rongeurs du Miocène supérieur de Chorora (Ethiopie): Cricetidae, Rhizomyidae, Phiomyidae, Thryonomyidae, Sciuridae. Paleovertebrata 27, 203-216. Geraads, D., Alemseged, Z., Reed, D., Wynn J., Roman, D. C. 2004. The Pleistocene fatna (other than Primates) from Asbole, lowerAwash Valley, Ethiopia, and its envirenmental and biochronological implications. Geobies 37, 697718.

Gogolevskaya, I. K., Veniaminova, N. A., Kramerov, D. A. 2010. Nucleotide sequences of B1 SINE and 4.5SI RNA support a close relationship of zokors to blind mole rats (Spalacinae) and bamboo rats (Rhizomyinae). Gene 460, 30-38.

Goloboff, P., Farris, J. 2001. Methods for quick consensus estimation. Cladistics 17, 26-34.

Goloboff, P., Farris, J. S., Källersjö, M., Oxelman, B., Ramírez, M. J., Szumika C. A. 2003. Improvements to resampling measures of group support. Cladistics, 19, 324332.

Goloboff, P., Farris, J., Nixon K. C. 2008. TNT, a free program for phylogenetic analysis. Cladistics 24, 774-786.

Gray, J.E. 1831. Characters of three new genera, including two new species of Mammalia from China. Proc. Comm. Zool. Soc. London 1, 94-98.

| Gupta, S. S., Verma, B. C., Tewari, A. P. 1978. A new fossil rodent Rhizomyoides saketiensis sp. nov. from the Tatrot member (Astian) of Siwalik fossil park, Saketi, Sirmur distt, Himachal Pradesh. J. Paleont. Soc. India 21-22, 112-115.

Haile-Selassie, Y., Wolde Gabriel, G., White, T. D., Bernor, R. L., DeGusta, D. L., Renne, P., Hart, W. K., Vrba, E., Ambrose, S., Howell, F. C. 2004. Mio-Pliocene mammals from the Middle Awash, Ethiopia. Geobios 37, 536-552.

Heck, J. G. 1851a. Iconographic Encyclopaedia of Science, Literature, and Art. Vol II: Botany, Zoology, Anthropology, and Surgery. New York, R. Garrigue. 
Heck, J. G. 1851b. Iconographic Encyclopaedia of Science, Literature, and Art. Vol I: Mathematics and Astronomy, Physics and Meteorology, Chemistry, Mineralogy, Geognosy and Geology. New York, R. Garrigue.

Heuglin, T. von, Fitzinger, L. J. 1866. Systematische Übersicht der Säugethiere Nordost- Afrika's mit Einschluß der arabischen Küste, des rothen Meeres, der Somáli- und der Nilquellen- Länder, südwärts bis zum vierten Grade nördlicher Breite. Sitzungsberichte Math.-Nat. Classe Kais. Akad. Wissensch., Abt. 1. 54, 537611.

Hinton, M. A. C. 1933. Diagnoses of new genera and species of rodents from Indian Tertiary deposits. Ann. Mag. nat. Hist. Ser. 10. 12, 620-622.

Hodgson, B.H.1841. New species of Rhizomys discovered in Nepal. Calcutta J. Nat. Hist. 2, 60-62.

IUCN. 2010. IUCN red list of threatened species. Version 2010.1. Available at www.iucnredlist.org

International Commission on Zoological Nomenclature. 1999. International Code of Zoological Nomenclature. Natural History Museum London, Fourth Edition. The Natural History Museum, London.

Jacobs, L. L. 1978. Fossil Rodents (Rhizomyidae and Muridae) from Neogene Siwalik deposits, Pakistan. Mus. North. Ariz. Bull. 52, 1-103.

Jacobs, L. L., Flynn, L. J. and Dows, W. R. 1989. Neogene rodents of Southern Asia. Nat. Hist. Mus. Los Angeles County, Science Series 33, 157-177.

Jacobs L. L., Flynn L. J., Downs W. R. \& Barry J. C. 1990. Quo vadis, Antemus? The Siwalik muroid record. In: Lindsay, E. H., Fahlbusch, V., Mein, P. (Eds.), European Neogene mammal chronology. Plenum Press, New York. pp. 573-586.

Jansa, S. A., Weksler, M. 2004. Phylogeny of muroid rodents: relationships within and among major lineages as determined by IRBP gene sequences. Mol. Phylogenet. Evol. 31, 256-276.

Lang, J., Lavocat, R. 1968. Première découverte d'une faune de vertébrés dans le tertiaire d'Afghanistan et datation de la série de Bamian. C.R. Acad. Sci., Série D 266, 79-82. 
Lavocat, R. 1978. Rodentia and Lagomorpha. In: Maglio, V.J., Cooke, H.B.S. (Eds.), Evolution of African mammals. Harvard University Press, Cambridge, MA, pp. 6989.

Lindsay, E. H. 1996. A new eEumyarionine cricetid from Pakistan. Acta Zool. Cracov. $39,27-40$.

Lindsay, E. H., Flynn, L. J., Cheema, I. U., Barry, J. C., Downing, K., Rajpar, A. R., Raza, S. M. 2005. Will Downs and the Zinda Pir Dome. Palaeontol. Electron. 8, 19A, $18 \mathrm{pp}$.

López-Antoñanzas, R. 2009. First Potwarmus from the Miocene of Saudi Arabia and the early phylogeny of murines (Rodentia: Muroidea). Zool. J. Linn. Soc. 156, 664679.

López-Antoñanzas, R. 2011. First Diatomyid out of Asia. Naturwissenschaften 98, $117-$ 123.

López-Antoñanzas, R. 2012. Dental morphology and wear pattern in Tachyoryctes (Spalacidae, Rodentia). Mammalia. 72.

López-Antoñanzas, R., Sen, S. 2006. New jumping mouse (Rodentia, Zapodidae) from the Lower Miocene of Saudi Arabia and a contribution to the knowledge of zapodid phylogeny. J. Vertebr. Paleont. 26, 170-181.

López-Antoñanzas, R., Knoll, F. 2011. A comprehensive phylogeny of the gundis (Ctenodactylinae, Ctenodactylidae). J. Syst. Paleontol. 9, 379-398.

López-Antoñanzas, R., Wesselman, H. B. In press. Tachyoryctes makooka (Tachyoryctini, Spalacidae, Rodentia) and its bearing on the phylogeny of the Tachyoryctini. Paleontology.

López-Antoñanzas, R., Sen, S., Mein, P. 2004. Systematics and phylogeny of the canerats (Rodentia, Thryonomyidae). Zool. J. Linn. Soc. 142, 423-444.

Lydekker, R. 1878. Notice of Siwaliks mammals. Rec. Geol. Sur. India 6, 64-104.

Lydekker, R. 1884. Rodents and new ruminants from the Siwaliks, and synopsis of Mammalia. Palaeontol. Indica 10, 105-134.

Lydekker, R. 1885. Catalogue fossil Mammalia British Museum (Natural History), Part 1. British Museum (Natural History), London.

McKenna, M. C., Bell, S. K. 1997. Classification of Mammals above the Species level. Columbia University Press, New York. 
Maddison, W. P., Maddison, D. R. 2009. Mesquite: a modular system for evolutionary analysis, Version 2.6. Mesquite Project, Vancouver.

Mein, P., Freudenthal, M. 1971. Les Cricetidae (Mammalia, Rodentia) du Néogène moyen du Vieux-Collonges. Partie 1, Le genre Cricetodon Lartet, 1851. Scripta Geol. $\underline{5,1-51 .}$

Mein, P., Ginsburg, L. 1985. Les rongeurs miocènes de Li (Thaïlande). C.R. Acad. Sci., Série II 301, 1369-1374.

Mein, P., Ginsburg, L. 1997. Les mammifères du gisement miocène inférieur de Li Mae Long, Thaïlande: systematique, biostratigraphie et paléoenvironnement.

Geodiversitas 19, 783-844.

Miller, G.S., Gidley, J.W. 1918. Synopsis of the supergeneric groups of rodents. J. Wash. Acad. Sci. 8, 431-448.

Misonne, X. 1971. Order Rodentia. In: Meester, J., Setzer, H.W. (Eds.), The Mammals of Africa: an identification manual. Smithsonian Institution Press, Washington, 1-39. Munthe, J. 1980. Rodents of the Miocene Daud Khel Local Fauna, Mianwali District, Pakistan. Part 1. Sciuridae, Gliridae, Ctenodactylidae, and Rhyzomyidae. Milwaukee Publ. Mus. Contr. Biol. Geol. 34, 1-36.

Musser, G. G., Carleton, M. D. 1993. Family Muridae. In: Wilson, D. E. Reeder, D. M. Formatted: English (U.S.) (Eds.), Mammal Species of the World, Second Edition. The Johns Hopkins University Press, Maryland, pp. 501-755.

Musser, G. G., Carleton, M. D. 2005. Superfamily Muroidea. In: Wilson D. E., Reeder, D. M. (Eds.), Mammal Species of the World, Third Edition. The Johns Hopkins University Press, Maryland, pp.894-1531.

Norris, R. W., K. Zhou, C. Zhou, G. Yang, C. W. Kilpatrick, R. L. Honeycutt. 2004. The phylogenetic position of the zokors (Myospalacinae) and comments on the families of muroids (Rodentia). Mol. Phy. Evol. 31, 972-978.

Nowak, R. M. 1999. Muridae: Rats, Mice, Hamsters, Voles, Lemmings, and Gerbils. In: Nowak R. M. (Ed.), Walker's mammals of the World, $6^{\text {th }}$ Edition. The Johns Hopkins University Press, Maryland, pp.1344-1616.

Palmer, T. S. 1897. A list of the generic and family names of rodents. Proc. Biol.Soc. Wash. XI, 241-270. 
| Parmar, V., Prasad, G.V.R. 2006. Middle Miocene rhizomyid rodent (Mammalia) from the Lower Siwalik Subgroup of Ramnagar, Udhampur District, Jammu and Kashmir, India. N. Jb. Geol. Paläont., Abh. 6, 371-384.

Prasad, K. N. 1968. The vertebrate fauna from the Siwalik beds of Haritalyangar, Himachal Pradesh, India. Palaeont. Indica 39, 1-79.

Raffles, T.S. 1821. Descriptive Catalogue of a Zoological Collection. Trans. Linn. Soc. Lond. XIII 239-274.

Rahm, U.1980. Die Afrikanische Wurzelratte Tachyoryctes. Ziemsen, A., Lutherstadt Wittenberg.

Rüppell, E. 1836. Neue Wirbelthiere zu der Fauna von Abyssinien gehörig. Part 7. Schmerber, S., Frankfurt am Main, pp.17-36.

Rüppell, E. 1842. Säugethiere aus der Ordnung der Nager, beobachtet im nordöstlichen Africa. Mus. Senckenb. 3, 99-116.

Sabatier, M. 1978. Un nouveau Tachyoryctes (Mammalia, Rodentia) du bassin Pliocene de Hadar (Ethiopie). Geobios 11, 95-99.

Sabatier, M. 1979. Les rongeurs des sites zà hominides de Hadar et Melka-Kunturé (Ethiopie). PhD thesis: Université des Sciences et Techniques du Languedoc.

Sabatier, M. 1982. Les rongeurs des sites pléistocènes de Melka-Kunturé, Ethiopie, Abbay 11, 45-64.

Sehgal, R. K., Patnaik, R. In press. New muroid rodent and Sivapithecus dental remains from the Lower Siwalik deposits of Ramnagar (JandK, India): Age implication, Quatern. Int.

Sen, S. 1983. Rongeurs et lagomorphes du gisement pliocène de Pul-e Charkhi, bassin de Kabul, Afghanistan. Bull. Mus. Hist. Nat. Paris Séries 5C, 33-74.

Simpson, G. G. 1945. The principles of classification and a classification of mammals.

Formatted: French (France) Bull. Am. Mus. Nat. Hist. 85, 1-350.

Teilhard de Chardin, P. 1942. New rodents of the Pliocene and lower Pleistocene of north China. Pub. Inst. Géo-Biol. 9, 1-101.

Thomas, O. 1896. On the genera of rodents: an attempt to bring up to date the current arrangement of the Order. Proc. Zool. Soc. Lond. 1012-1028.

Thomas, O. 1915a. Notes on the Asiatic Bamboo-Rats (Rhizomys, etc.). Ann. Mag. Nat. Hist. XVI, 56-61. 
Thomas, O. 1915b. Further notes on Asiatic Bamboo-Rats. Ann. Mag. Nat. Hist. XVI, 313-317.

Tong, H., Jaeger J.J. 1993. Muroid rodents from the Middle Miocene Fort Ternan locality (Kenya) and their contribution to the phylogeny of muroids.

Palaeontographica, Abteilung A 229, 51-73.

Tullberg, T. 1899. Über das System der Nagethiere: eine phylogenetische Studie. Akademische Buchdruckerei.

Vasishat, R. N., Gaur R., Chopra S. R. K. 1978. Community structure of Middle Sivalik vertebrates from Haritalyangar (H.P.), India. Palaeogeogr. Palaeocl. Palaeoeco. 23, 131-140.

Welcomme J. L., Ginsburg, L. 1997. Mise en evidence de l'Oligocène sur le territoire des Bugti (Balouchistan, Pakistan). C.R. Acad. Sci., Série IIa 325, 999-1004.

Welcomme, J. L., Benammi, M., Crochet, J. Y., Marivaux, L., Métais, G., Antoine, P. O., Balouch, I. 2001. Himalayan Forelands: palaeontological evidence for Oligocene detritic deposits in Bugti Hills (Balochistan, Pakistan). Geol. Mag. 138, 397-405.

Wesselman, H. B., Black, M. T., Asnake, M. 2009. Small Mammals. In: Haile-Selassie, Y., WoldeGabriel, G. (Eds.), Ardipithecus kadabba: Late Miocene Evidence from the Middle Awash, Ethiopia (The Middle Awash Series). University of California Press, London, pp. 105-133.

Wessels, W. 2009. Miocene rodent evolution and migration. Muroidea from Pakistan, Turkey and Northern Africa. Geol. Ultraiectina 307, 1-290.

Wessels, W., de Bruijn H. 2001. Rhizomyidae from the Lower Manchar Formation (Miocene, Pakistan). Ann. Carnegie Mus. 70, 143-168.

Wessels,W., de Bruijn, H., Hussain, S. T., Leinders, J. 1982. Fossil rodents from the Chinji Formation, Banda Daud Shah, Kohat, Pakistan. Proc. Kon. nederl. Akad. Wetensch. B 85, 337-364.

Wessels, W., Fejfar, O., Peláez-Campomanes, P., De Bruijn, H. 2003. Miocene small mammals from Jebel Zelten, Libya. Coloq. Paleont.Vol. Extr., 699-715.

Wessels, W., Fejfar, O., Peláez-Campomanes, P., Van Der Meulen, A., De Bruijn, H., El-Arnauti, A. 2008. The age of the small mammal faunas from Jabal Zaltan, Libya. Garyounis Sci. Bull., spec. issue 5, 129-138. 
Winge, H. 1887. Jordfundne og nulevende Gnavere (Rodentia) fra Lagoa Santa, Minas Geraes, Brasilien. E Museo Lundii, University of Copenhagen 1, 1-178.

Wood, A. E. 1937. Fossil rodents from the Siwalik beds of India. Am. J. Sci. 34, 64-76. 
Fig. 1. Distribution of the extant Rhizomyines (after IUCN data) and fossil localities. 1, Taoyang, Yushe Basin, Shanxi, China; 2, Lufeng, Chuxiong Yi, Yunnan, China; 3, Mae Long and Mae Moh, Lamphang Province, Thailand; 4, 5, Haritalyangar, India; 6, Punjab, India; 7, Ramnagar, India; 8, Potwar Plateau (Dhok Pathan-Khaur, ChinjiNagri, Tatrot-Hasnot regions), Pakistan; 9, Banda Daud Shah (Pakistan); 10, Zinda Pir Dome (Pakistan); 11, 12, Sind (Pakistan); 13, Lataband, Sarobi Basin, Afghanistan; 14, Pul-e Charkhi Kabul, Afghanistan; 15, Bamian Basin, Afghanistan; 16, Jebel Zelten (Libya); 17, Kada Hadar, Hadar Formation, Ethiopia; 18, Digiba Dora Vertebrate Locality 1 (Middle Awash, Ethiopia); 19, Melka Kunturé, Ethiopia; 20, Nakali, Kenya; 21, Fort Ternan, Kenya.

Fig. 2. Rhizomyidae dental terminology used in this paper. Prokanisamys arifi-A. Left M1, H-GSP 8311/4359. —B. Left M2, H-GSP 8311/4369. —C. Left M3, H-GSP 8311/4381. —D. Left m1, H-GSP 8311/4294. —E. Left m2, H-GSP 8311/4316. —F., Left m3, H-GSP 8311/4334. Scale bar equals $1 \mathrm{~mm}$.

Fig. 3. Cheek teeth of Rhizomys sinensis, Cannomys badius and Tachyoryctes splendens. - A. Lower cheek teeth of Rhizomys sinensis (specimen C.G. 1912-851) with m1-m3. - B. Upper cheek teeth of the same specimen with M1-M3. - C. Lower cheek teeth of Cannomys badius (specimen C.G. 1860-382) with m1-m3. - D. Upper cheek teeth of the same specimen with M1-M3. - E. Lower cheek teeth of Tachyoryctes splendens (specimen C.G. 1993-217) with m1-m3. -F. Upper cheek teeth of the same specimen with M1-M3. Scale bar equals $2 \mathrm{~mm}$.

Fig. 4. Cheek teeth of Kanisamys nagrii, Kanisamys potwarensis, Miorhizomys tetracharax, Rhizomys (Brachyrhizomys) sansius.-A. Maxilla of Kanisamys nagrii (specimen AMNH 30000) with right M1-M3.-B. Maxilla of Kanisamys nagrii (specimen AMNH 30000) with left M1-M2. - C. Mandible of Kanisamys nagrii (specimen AMNH 39323) with m1-m3. - D. Maxilla of Kanisamys potwarensis (specimen AMNH 39321) with M1-M3. -E. Mandible of Miorhizomys tetracharax 
(specimen AMNH 39325) with m1-m3). -F. Mandible of Rhizomys (Brachyrhizomys) shansius (specimen AMNH 117337) with m1-m3. - G. Maxilla of Rhizomys (Brachyrhizomys) shansius (specimen AMNH 117337).

Fig. 5. Reconstruction of Bathyergus splendens provided by Rüppell (1836).

Fig. 6. Relationships of extant and extinct Rhizomyines provided by Flynn (1990).

Fig. 7. Consensus trees generated by the cladistic analysis of the Rhizomyidae performed in this paper (matrix in Appendix 2). - A. strict and semi-strict consensus trees, nodes are designed in bold by numbers 40 to 62, Bremer and Relative Bremer Indices are showed at the appropriate nodes. $-\mathrm{B}$, majority-rule consensus tree. The trees have a length of 158 steps, a consistency index (CI) of 0.456 and a retention index (RI) of 0.819 .

Fig. 8. Calibrated phylogeny based on the cladistic relationships presented in Fig. 7 and the recorded temporal ranges (black). Grey bars represent missing ranges and missing ancestral lineages. Error bars indicate age uncertainty. Chronostratigraphical data from Sabatier (1979), de Bruijn et al. (1981), Flynn (1982a, 1983, 1986), Flynn et al. (1983, 1990, 1995, 2009), Sen (1983), Wessels et al. (2003), Chaimanee et al. (2007), Wesselman et al (2009) and Wessels (2009).

Fig. 9 Geographic distribution of rhizomyine rodents plotted onto the strict consensus of the most parsimonious trees of our analysis using Mesquite ver. 2.6 (Maddison and Maddison, 2009) as a two-state character. 
Fig. 1. Distribution of the extant Rhizomyines (after IUCN data) and fossil localities. 1, Taoyang, Yushe Basin, Shanxi, China; 2, Lufeng, Chuxiong Yi, Yunnan, China; 3, Mae Long and Mae Moh, Lamphang Province, Thailand; 4, 5, Haritalyangar, India; 6, Punjab, India; 7, Ramnagar, India; 8, Potwar Plateau (Dhok Pathan-Khaur, Chinji-Nagri, Tatrot-Hasnot regions), Pakistan; 9, Banda Daud Shah (Pakistan); 10, Zinda Pir Dome (Pakistan); 11, 12, Sind (Pakistan); 13, Lataband, Sarobi Basin, Afghanistan; 14, Pul-e Charkhi Kabul, Afghanistan; 15, Bamian Basin, Afghanistan; 16, Jebel Zelten (Libya); 17, Kada Hadar, Hadar Formation, Ethiopia; 18, Digiba Dora Vertebrate Locality 1 (Middle Awash, Ethiopia); 19, Melka Kunturé, Ethiopia; 20, Nakali, Kenya; 21, Fort Ternan, Kenya. $96 \times 52 \mathrm{~mm}(300 \times 300$ DPI $)$ 


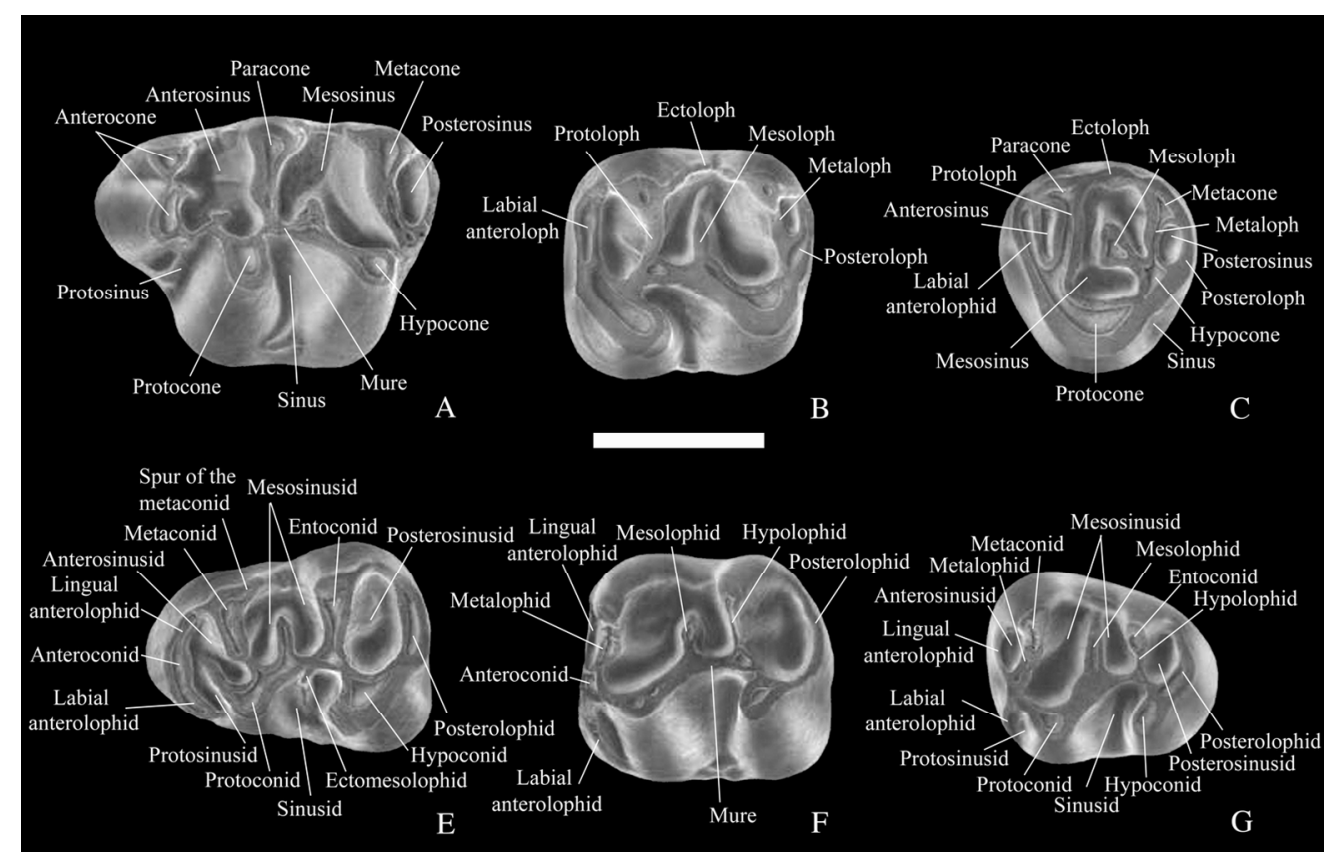

Fig. 2. Rhizomyidae dental terminology used in this paper. Prokanisamys arifi-A. Left M1, H-GSP 8311/4359. -B. Left M2, H-GSP 8311/4369. -C. Left M3, H-GSP 8311/4381. -D. Left m1, H-GSP 8311/4294. -E. Left m2, H-GSP 8311/4316. -F., Left m3, H-GSP 8311/4334. Scale bar equals 1 mm. $134 \times 86 \mathrm{~mm}(300 \times 300 \mathrm{DPI})$ 
Fig. 3. Fig. 3. Cheek teeth of Rhizomys sinensis, Cannomys badius and Tachyoryctes splendens. -A. Lower cheek teeth of Rhizomys sinensis (specimen C.G. 1912-851) with m1-m3. -B. Upper cheek teeth of the same specimen with M1-M3. - C. Lower cheek teeth of Cannomys badius (specimen C.G. 1860-382) with m1-m3. -D. Upper cheek teeth of the same specimen with M1-M3. - E. Lower cheek teeth of Tachyoryctes splendens (specimen C.G. 1993-217) with m1-m3. -F. Upper cheek teeth of the same specimen with M1M3. Scale bar equals $2 \mathrm{~mm}$. $102 \times 58 \mathrm{~mm}(300 \times 300 \mathrm{DPI})$ 


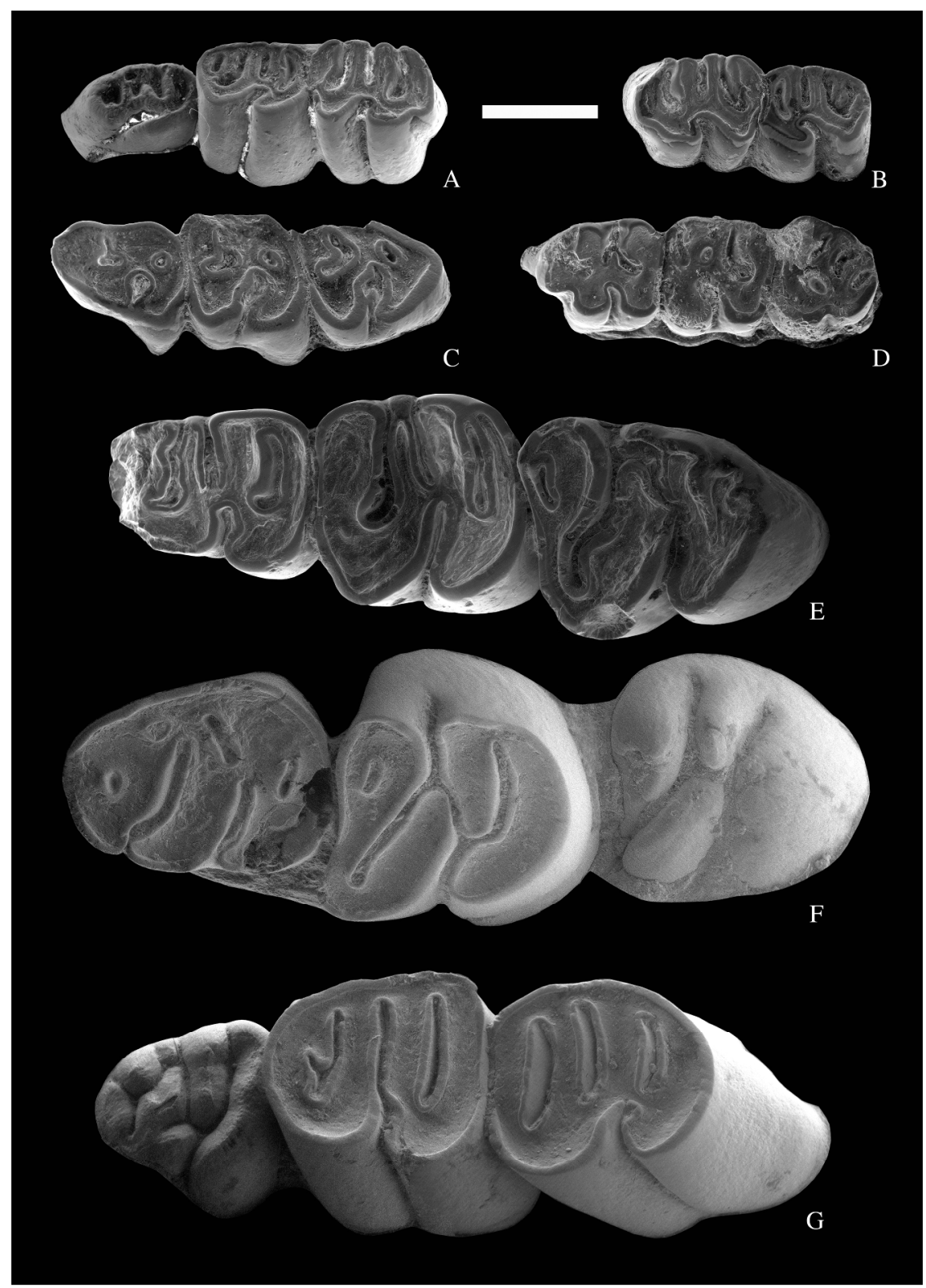

Fig. 4. Cheek teeth of Kanisamys nagrii, Kanisamys potwarensis, Miorhizomys tetracharax, Rhizomys (Brachyrhizomys) sansius.-A. Maxilla of Kanisamys nagrii (specimen AMNH 30000) with right M1-M3.-B. Maxilla of Kanisamys nagrii (specimen AMNH 30000) with left M1-M2. -C. Mandible of Kanisamys nagrii (specimen AMNH 39323) with m1-m3. -D. Maxilla of Kanisamys potwarensis (specimen AMNH 39321) with M1-M3. -E. Mandible of Miorhizomys tetracharax (specimen AMNH 39325) with m1-m3). -F. Mandible of Rhizomys (Brachyrhizomys) shansius (specimen AMNH 117337) with m1-m3. - G. Maxilla of Rhizomys (Brachyrhizomys) shansius (specimen AMNH 117337). $250 \times 350 \mathrm{~mm}(300 \times 300 \mathrm{DPI})$ 


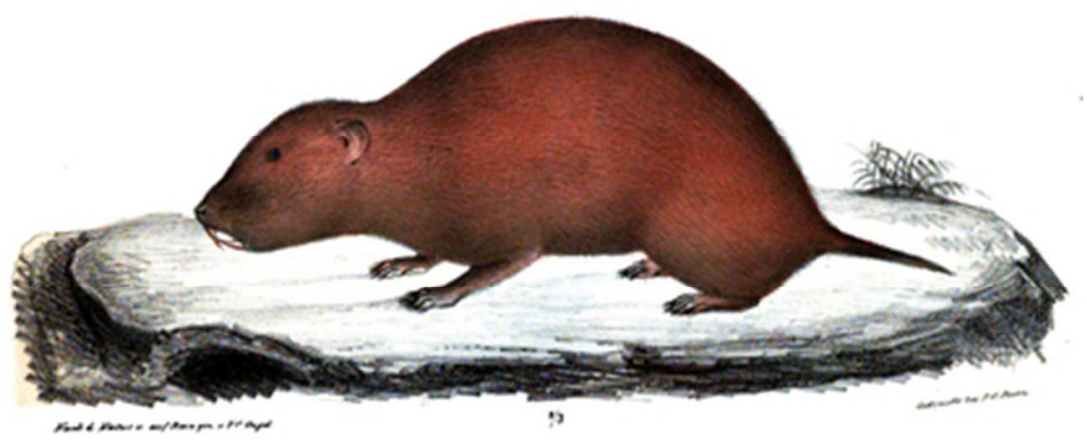

Fig. 5 Reconstruction of Bathyergus splendens provided by Rüppell (1836) $35 \times 14 \mathrm{~mm}(300 \times 300 \mathrm{DPI})$ 
1

2

3

4

5

6

7

9

10

11

12

13

14

15

16

17

18

19

20

21

22

23

24

25

26

27

28

29

30

31

32

33

34

35

36

37

38

39

40

41

42

43

44

45

46

47

48

49

50

51

52

53

54

55

56

57

58

59

60

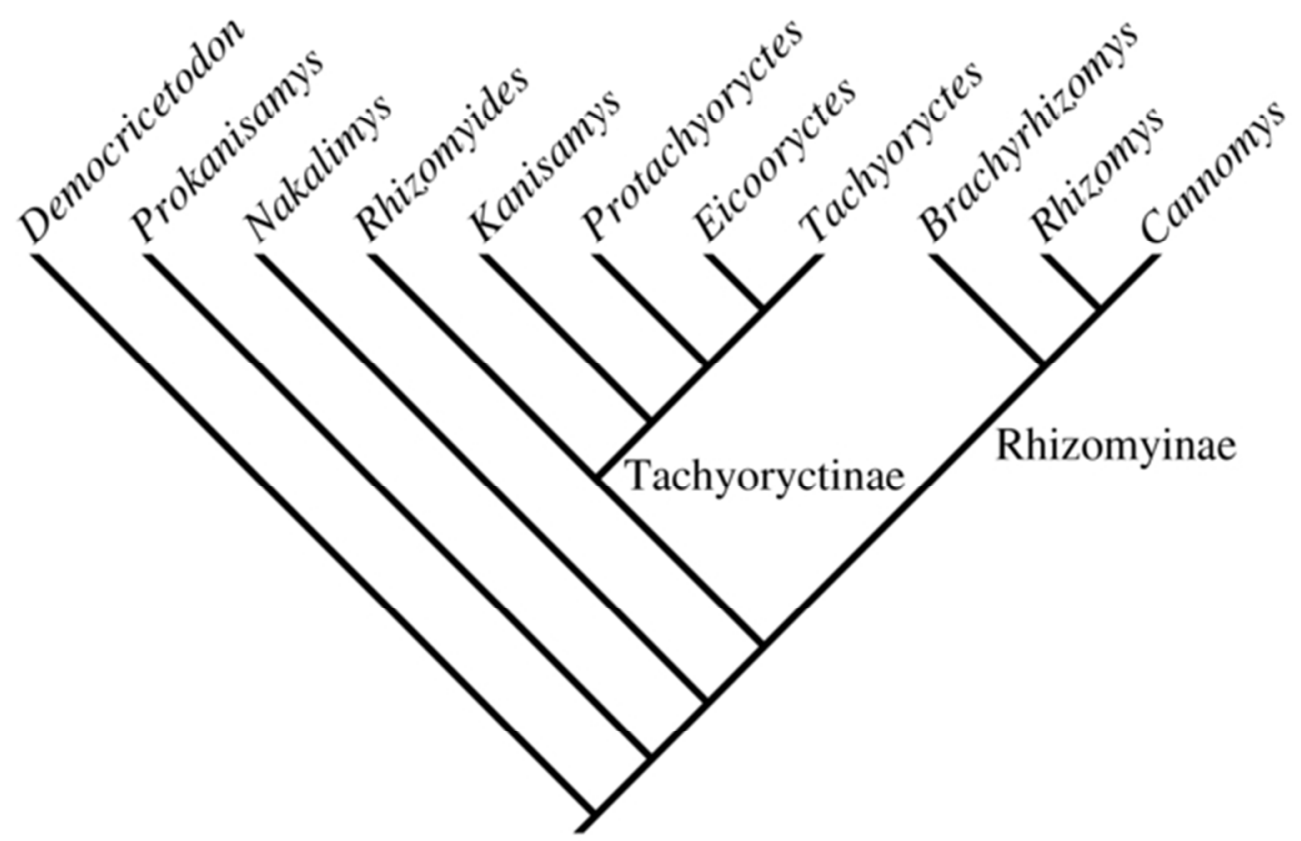

Fig. 6. Relationships of extant and extinct Rhizomyines provided by Flynn (1990). $55 \times 36 \mathrm{~mm}(300 \times 300 \mathrm{DPI})$ 
Debruijnia arpati

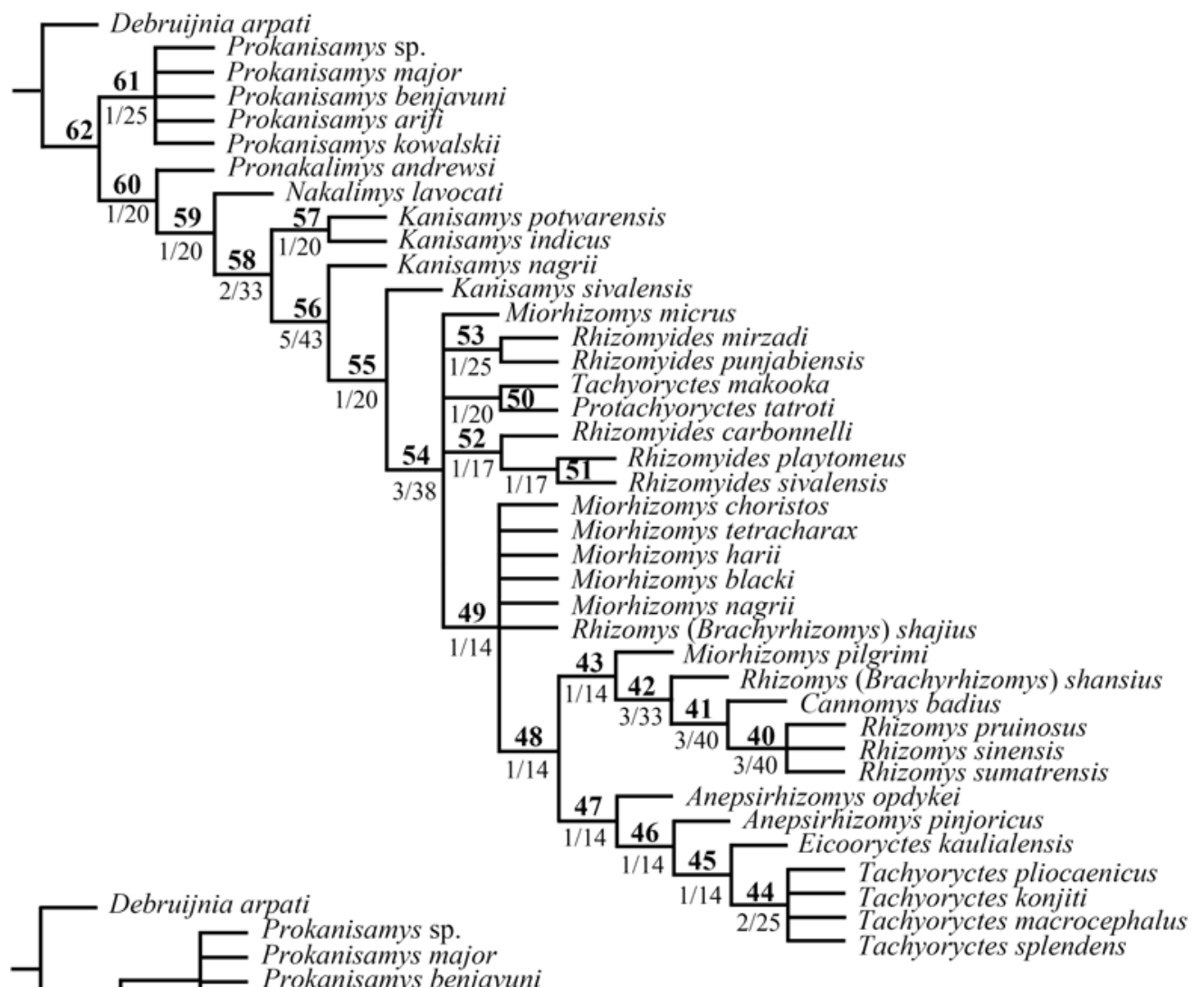


Africa

- Asia

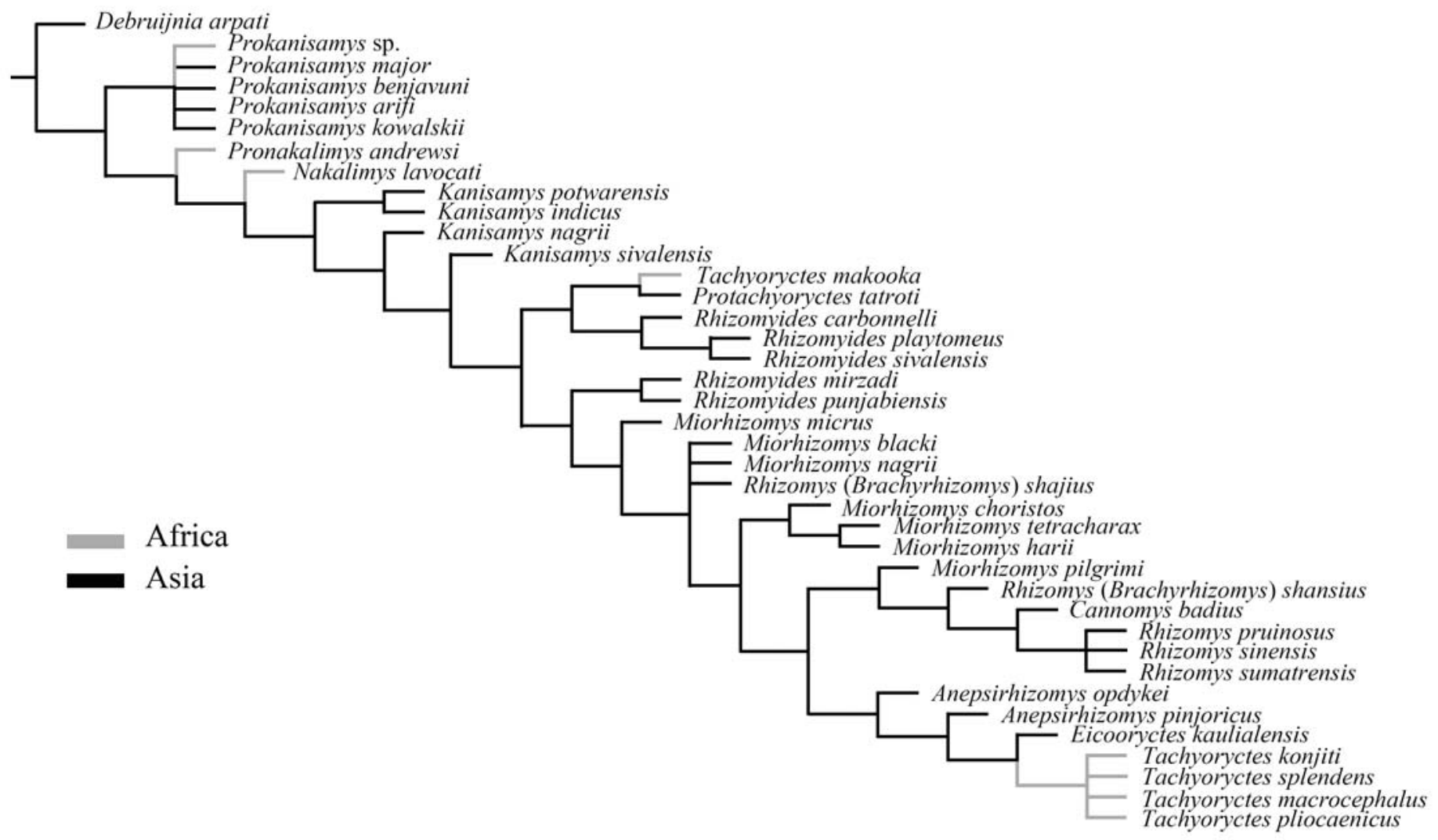




\section{$\underline{\text { Table } 1}$}

$\underline{\text { Character/taxon matrix used in the analysis of relationships of all extinct and extant }}$

species of Rhizomyinae. Characters are listed in material and methods. Character

scoring: 0,1 and 2, conditions of character; -, uncodable character; ?, character state

$\underline{\text { uncertain. }}$

Table 2

Synapomorphies common to the 32MPTs plotted on the strict consensus tree. Exclusive synapomorphies are indicated in bold. Italics indicate ambiguous synapomorphies.

Node numbers are shown in Figure 7. 
$\begin{array}{llllllllllllllllllllllllllllllllllllllllllll}1 & 2 & 3 & 4 & 5 & 6 & 7 & 8 & 9 & 10 & 11 & 12 & 13 & 14 & 15 & 16 & 17 & 18 & 19 & 20 & 21 & 22 & 23 & 24 & 25 & 26 & 27 & 28 & 29 & 30 & 31 & 32 & 33 & 34 & 35 & 36 & 37 & 38 & 39 & 40 & 41 & 42 & 43 & 44\end{array}$

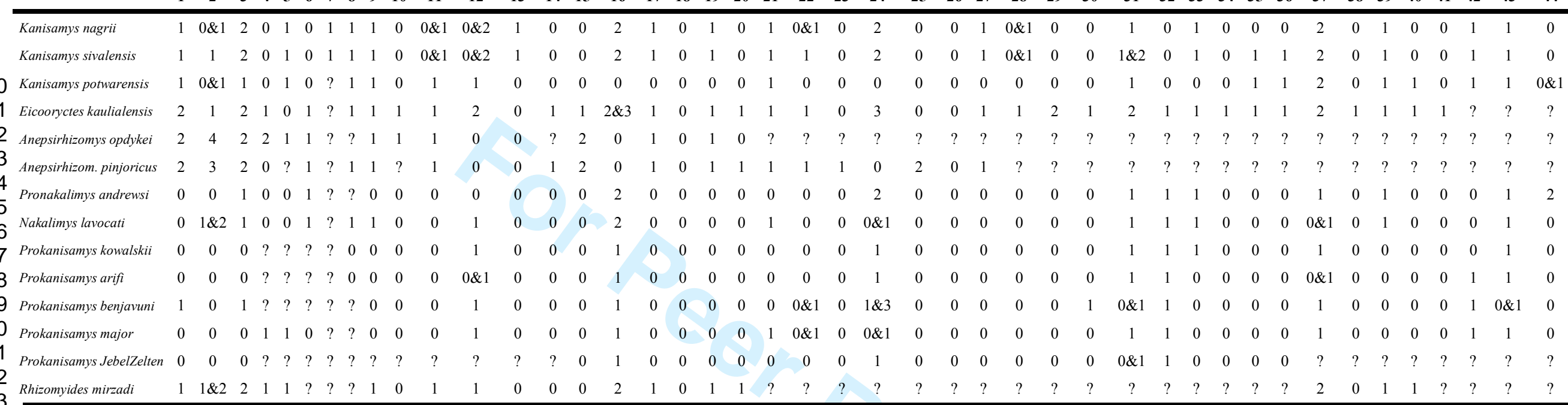
24 25 27
28 29 30 31 


\begin{tabular}{|c|c|c|}
\hline & Acctran & Deltran \\
\hline \multicolumn{3}{|l|}{ Rhizomys sumatrensis } \\
\hline Rhizomys sinensis & $21(1 \rightarrow 0)$ & $21(1 \rightarrow 0)$ \\
\hline \multicolumn{3}{|l|}{ Rhizomys pruinosus } \\
\hline Rhizomys (Brachyrh.) shansius & $42(2 \rightarrow 1)$ & \\
\hline Rhizomys (Brachyrh.) shajius & $16(0 \rightarrow 2)$ & $15(0 \rightarrow 1) ; 16(0 \rightarrow 2)$ \\
\hline Cannomys badius & $4(2 \rightarrow 1)$ & $2(3 \rightarrow 0 \& 1) ; 4(2 \rightarrow 1)$ \\
\hline Miorhizomys nagrii & $4(2 \rightarrow 1) ; \mathbf{1 0}(\mathbf{1} \rightarrow \mathbf{0}) ; 15(1 \rightarrow 0) ; 21(1 \rightarrow 0) ; \mathbf{2 9}(\mathbf{1} \rightarrow \mathbf{0}) ; 32(1 \rightarrow 0) ; \mathbf{3 8}(\mathbf{1} \rightarrow \mathbf{0})$ & $\begin{array}{l}4(2 \rightarrow 1) ; \mathbf{1 0}(\mathbf{1} \rightarrow \mathbf{0}) ; 14(0 \rightarrow 1) ; 21(1 \rightarrow 0) ; \mathbf{2 9}(\mathbf{1} \rightarrow \mathbf{0}) ; 32(1 \rightarrow 0) ; \\
\mathbf{3 8}(\mathbf{1} \rightarrow \mathbf{0})\end{array}$ \\
\hline Miorhizomys micrus & $2(2 \rightarrow 1) ; 4(0 \rightarrow 1) ; 8(1 \rightarrow 2) ; 20(1 \rightarrow 0) ; 25(0 \rightarrow 1)$ & $2(2 \rightarrow 1) ; 4(0 \rightarrow 1) ; 8(1 \rightarrow 2) ; 25(0 \rightarrow 1)$ \\
\hline Miorhizomys blacki & $15(1 \rightarrow 0)$ & \\
\hline \multicolumn{3}{|l|}{ Miorhizomys pilgrimi } \\
\hline Miorhizomys harii & $4(2 \rightarrow 1) ; 14(1 \rightarrow 0) ; 16(0 \rightarrow 1) ; \mathbf{1 7}(\mathbf{1} \rightarrow \mathbf{0})$ & $4(2 \rightarrow 1) ; 15(0 \rightarrow 1) ; 16(0 \rightarrow 1) ; \mathbf{1 7}(\mathbf{1} \rightarrow \mathbf{0})$ \\
\hline Miorhizomys tetracharax & $\begin{array}{l}14(1 \rightarrow 0) ; 20(1 \rightarrow 0) ; 23(0 \rightarrow 1) ; 24(2 \rightarrow 4) ; 25(1 \rightarrow 2) ; 26(0 \rightarrow 1) ; \\
27(\mathbf{1} \rightarrow \mathbf{0}) ; 28(1 \rightarrow 0) ; \mathbf{4 1}(\mathbf{1} \rightarrow \mathbf{0})\end{array}$ & $\begin{array}{l}15(0 \rightarrow 1) ; 20(1 \rightarrow 0) ; 23(0 \rightarrow 1) ; 24(2 \rightarrow 4) ; 25(1 \rightarrow 2) ; 26(0 \rightarrow 1) ; \\
27(\mathbf{1} \rightarrow \mathbf{0}) ; 28(1 \rightarrow 0) ; \mathbf{4 1}(\mathbf{1 \rightarrow 0})\end{array}$ \\
\hline Miorhizomys choristos & $\begin{array}{l}15(1 \rightarrow 2) ; 16(0 \rightarrow 4) ; 23(0 \rightarrow 1) ; 24(2 \rightarrow 4) ; 25(1 \rightarrow 2) ; \\
26(0 \rightarrow 1) ; \mathbf{3 1}(2 \rightarrow \mathbf{0}) ; 37(2 \rightarrow 3) ; 42(1 \rightarrow 0)\end{array}$ & $\begin{array}{l}14(0 \rightarrow 1) ; 15(0 \rightarrow 2) ; 16(0 \rightarrow 4) ; 23(0 \rightarrow 1) ; 24(2 \rightarrow 4) ; 25(1 \rightarrow 2) ; \\
26(0 \rightarrow 1) ; 31(2 \rightarrow 0) ; 37(2 \rightarrow 3) ; 42(1 \rightarrow 0)\end{array}$ \\
\hline Protachyoryctes tatroti & $34(1 \rightarrow 0)$ & $5(1 \rightarrow 0) ; \mathbf{3 4}(\mathbf{1} \rightarrow \mathbf{0})$ \\
\hline Tachyoryctes makooka & $10(0 \rightarrow 1)$ & $10(0 \rightarrow 1) ; 43(1 \rightarrow 2) ; 44(0 \rightarrow 2)$ \\
\hline T. pliocaenicus & $1(2 \rightarrow 1) ; \mathbf{1 2}(\mathbf{3} \rightarrow \mathbf{2}) ; 20(1 \rightarrow 0) ; \mathbf{2 5}(\mathbf{2} \rightarrow \mathbf{1}) ; 28(1 \rightarrow 0)$ & $1(2 \rightarrow 1) ; \mathbf{1 2}(\mathbf{3} \rightarrow \mathbf{2}) ; 20(1 \rightarrow 0) ; \mathbf{2 5}(\mathbf{2} \rightarrow \mathbf{1}) ; 28(1 \rightarrow 0)$ \\
\hline T.macrocephalus & $2(1 \rightarrow 2)$ & $2(1 \rightarrow 2)$ \\
\hline \multicolumn{3}{|l|}{ Tachyoryctes splendens } \\
\hline Rhizomyides sivalensis & $28(1 \rightarrow 0)$ & \\
\hline Rhizomyides punjabiensis & $\mathbf{3}(\mathbf{2} \rightarrow \mathbf{1}) ; 11(1 \rightarrow 0)$ & $2(2 \rightarrow 1) ; \mathbf{3}(\mathbf{2} \rightarrow \mathbf{1}) ; 11(1 \rightarrow 0) ; 22(1 \rightarrow 0) ; 32(1 \rightarrow 0) ; 43(1 \rightarrow 2)$ \\
\hline Rhizomyides carbonnelli & $40(1 \rightarrow 0)$ & $28(0 \rightarrow 1) ; \mathbf{4 0}(\mathbf{1} \rightarrow \mathbf{0}) ; \mathbf{4 3}(\mathbf{1} \rightarrow \mathbf{0})$ \\
\hline Rhizomyides playtomeus & $15(0 \rightarrow 1)$ & $15(0 \rightarrow 1) ; 28(0 \rightarrow 1)$ \\
\hline Tachyoryctes konjiti & $1(2 \rightarrow 1)$ & $1(2 \rightarrow 1)$ \\
\hline Kanisamys indicus & $8(1 \rightarrow 0)$ & $8(1 \rightarrow 0)$ \\
\hline \multicolumn{3}{|l|}{ Kanisamys nagrii } \\
\hline Kanisamys sivalensis & & $2(0 \rightarrow 1)$ \\
\hline Kanisamys potwarensis & $12(0 \rightarrow 1) ; \mathbf{3 3}(\mathbf{1} \rightarrow \mathbf{0}) ; 35(0 \rightarrow 1) ; 36(0 \rightarrow 1) ; 40(0 \rightarrow 1)$ & $12(0 \rightarrow 1) ; \mathbf{3 3}(\mathbf{1} \rightarrow \mathbf{0}) ; 35(0 \rightarrow 1) ; 36(0 \rightarrow 1) ; 40(0 \rightarrow 1)$ \\
\hline Eicooryctes kaulialensis & $4(0 \rightarrow 1) ; \mathbf{1 5}(\mathbf{2} \rightarrow \mathbf{1}) ; \mathbf{2 3}(\mathbf{1 \rightarrow 0}) ; \mathbf{2 5}(\mathbf{2} \rightarrow \mathbf{0})$ & $4(0 \rightarrow 1) ; 12(0 \rightarrow 2) ; \mathbf{1 5}(\mathbf{2} \rightarrow \mathbf{1}) ; \mathbf{2 3}(\mathbf{1 \rightarrow 0}) ; 25(2 \rightarrow 0)$ \\
\hline Anepsirhizomys opdykei & $2(3 \rightarrow 4) ; 20(1 \rightarrow 0)$ & $2(3 \rightarrow 4) ; 20(1 \rightarrow 0)$ \\
\hline Anepsirhizom. pinjoricus & - & $24(2 \rightarrow 0)$ \\
\hline Pronakalimys andrewsi & $24(0 \rightarrow 2) ; 44(0 \rightarrow 2)$ & $24(0 \rightarrow 2) ; 44(0 \rightarrow 2)$ \\
\hline Nakalimys lavocati & $12(0 \rightarrow 1)$ & $2(0 \rightarrow 1 \& 2) ; 12(0 \rightarrow 1)$ \\
\hline Prokanisamys kowalskii & $33(0 \rightarrow 1) ; 42(1 \rightarrow 0)$ & $33(0 \rightarrow 1) ; 42(1 \rightarrow 0)$ \\
\hline \multicolumn{3}{|l|}{ Prokanisamys arifi } \\
\hline Prokanisamys benjavuni & $1(0 \rightarrow 1) ; \mathbf{3}(\mathbf{0} \rightarrow \mathbf{1}) ; 30(0 \rightarrow 1)$ & $1(0 \rightarrow 1) ; \mathbf{3}(\mathbf{0} \rightarrow \mathbf{1}) ; 30(0 \rightarrow 1)$ \\
\hline Prokanisamys major & $21(0 \rightarrow 1)$ & $4(0 \rightarrow 1) ; 21(0 \rightarrow 1)$ \\
\hline \multicolumn{3}{|l|}{ Prokanisamys sp. (Libya) } \\
\hline Rhizomyides mirzadi & $13(1 \rightarrow 0)$ & $13(1 \rightarrow 0)$ \\
\hline 40 & $2(0 \rightarrow 4) ; 31(2 \rightarrow 3) ; 37(2 \rightarrow 3) ; 43(2 \rightarrow 3)$ & $2(3 \rightarrow 4) ; \mathbf{3 1}(\mathbf{2} \rightarrow \mathbf{3}) ; 37(2 \rightarrow 3) ; \mathbf{4 3}(\mathbf{2} \rightarrow \mathbf{3})$ \\
\hline 41 & $1(1 \rightarrow 2) ; 2(3 \rightarrow 0) ; 12(0 \rightarrow 4) ; 26(0 \rightarrow 1)$ & $1(1 \rightarrow 2) ; \mathbf{1 2}(\mathbf{0} \rightarrow \mathbf{4}) ; 26(0 \rightarrow 1) ; 42(1 \rightarrow 2)$ \\
\hline 42 & $\mathbf{6}(\mathbf{1 \rightarrow 2}) ; 7(\mathbf{1} \rightarrow \mathbf{2}) ; 18(0 \rightarrow \mathbf{1}) ; 20(1 \rightarrow 0)$ & $\mathbf{6}(\mathbf{1 \rightarrow 2}) ; \mathbf{7}(\mathbf{1} \rightarrow \mathbf{2}) ; 10(1 \rightarrow 2) ; \mathbf{1 8}(\mathbf{0} \rightarrow \mathbf{1}) ; 20(1 \rightarrow 0)$ \\
\hline 43 & $10(1 \rightarrow 2) ; 16(0 \rightarrow 4) ; 24(0 \rightarrow 4)$ & $16(0 \rightarrow 4) ; 24(2 \rightarrow 4)$ \\
\hline 44 & $10(1 \rightarrow 2) ; \mathbf{1 2}(2 \rightarrow 3) ; 13(0 \rightarrow 1) ; 14(1 \rightarrow 0)$ & $10(1 \rightarrow 2) ; 12(0 \rightarrow 3) ; 13(0 \rightarrow 1) ; 14(1 \rightarrow 0) ; 42(1 \rightarrow 2)$ \\
\hline 45 & $2(3 \rightarrow 1) ; 12(0 \rightarrow 2) ; 16(0 \rightarrow 3) ; 24(0 \rightarrow 3)$ & $\mathbf{2}(\mathbf{3} \rightarrow \mathbf{1}) ; 5(1 \rightarrow 0) ; \mathbf{1 6}(\mathbf{0} \rightarrow \mathbf{3}) ; \mathbf{2 4}(\mathbf{2} \rightarrow \mathbf{3}) ; 29(1 \rightarrow 2)$ \\
\hline 46 & $\mathbf{4}(\mathbf{2} \rightarrow \mathbf{0}) ; 5(1 \rightarrow 0)$ & $\mathbf{4}(\mathbf{2} \rightarrow \mathbf{0}) ; 8(2 \rightarrow 1)$ \\
\hline 47 & $1(1 \rightarrow 2) ; 8(2 \rightarrow 1) ; 13(1 \rightarrow 0) ; 29(1 \rightarrow 2)$ & $1(1 \rightarrow 2) ; 13(1 \rightarrow 0)$ \\
\hline 48 & $\begin{array}{l}2(2 \rightarrow 3) ; 15(1 \rightarrow 2) ; 23(0 \rightarrow 1) ; 24(2 \rightarrow 0) ; 25(1 \rightarrow 2) ; 42(1 \rightarrow 2) ; \\
43(1 \rightarrow 2) ; \mathbf{4 4}(\mathbf{1} \rightarrow \mathbf{2})\end{array}$ & $\begin{array}{l}2(2 \rightarrow 3) ; 14(0 \rightarrow 1) ; 15(0 \rightarrow 2) ; 23(0 \rightarrow 1) ; 25(1 \rightarrow 2) ; 43(1 \rightarrow 2) ; \\
\mathbf{4 4}(\mathbf{1 \rightarrow 2})\end{array}$ \\
\hline 49 & $\begin{array}{l}\mathbf{4}(\mathbf{0 \rightarrow 2}) ; 8(1 \rightarrow 2) ; 10(0 \rightarrow 1) ; 14(0 \rightarrow 1) ; 15(0 \rightarrow 1) ; 16(2 \rightarrow 0) ; 25(0 \rightarrow 1) ; \\
28(0 \rightarrow 1) ; \mathbf{2 9}(\mathbf{0 \rightarrow 1}) ; 30(0 \rightarrow 1) ; \mathbf{3 8}(\mathbf{0 \rightarrow 1}) ; \mathbf{4 3}(\mathbf{2} \rightarrow \mathbf{1}) ; \mathbf{4 4}(\mathbf{0 \rightarrow 1})\end{array}$ & $\begin{array}{l}\mathbf{4}(\mathbf{0 \rightarrow 2}) ; 8(1 \rightarrow 2) ; 10(0 \rightarrow 1) ; 16(2 \rightarrow 0) ; 20(0 \rightarrow 1) ; 25(0 \rightarrow 1) ; \\
28(0 \rightarrow 1) ; \mathbf{2 9}(\mathbf{0 \rightarrow 1}) ; 30(0 \rightarrow 1) ; \mathbf{3 8}(\mathbf{0} \rightarrow \mathbf{1}) ; \mathbf{4 4}(\mathbf{0} \rightarrow \mathbf{1})\end{array}$ \\
\hline 50 & $5(1 \rightarrow 0) ; 12(0 \rightarrow 2) ; 15(0 \rightarrow 1) ; 20(1 \rightarrow 0) ; 44(0 \rightarrow 2)$ & $12(0 \rightarrow 2) ; 15(0 \rightarrow 1)$ \\
\hline 51 & $2(2 \rightarrow 3) ; 16(2 \rightarrow 0)$ & $2(2 \rightarrow 3) ; 16(2 \rightarrow 0)$ \\
\hline 52 & $5(1 \rightarrow 0) ; 13(1 \rightarrow 0) ; 28(0 \rightarrow 1) ; \mathbf{4 3}(\mathbf{2} \rightarrow \mathbf{0})$ & $5(1 \rightarrow 0) ; 13(1 \rightarrow 0) ; 20(0 \rightarrow 1)$ \\
\hline 53 & $2(2 \rightarrow 1) ; 4(0 \rightarrow 1) ; 12(0 \rightarrow 1) ; 22(1 \rightarrow 0) ; 32(1 \rightarrow 0)$ & $4(0 \rightarrow 1) ; 12(0 \rightarrow 1) ; 20(0 \rightarrow 1)$ \\
\hline 54 & $\begin{array}{l}2(1 \rightarrow 2) ; \mathbf{6}(0 \rightarrow 1) ; 20(0 \rightarrow 1) ; \mathbf{3 2}(\mathbf{0} \rightarrow \mathbf{1}) ; \mathbf{3 4}(\mathbf{0} \rightarrow \mathbf{1}) ; \mathbf{4 0}(\mathbf{0} \rightarrow \mathbf{1}) ; \mathbf{4 1}(\mathbf{0} \rightarrow \mathbf{1}) \\
43(1 \rightarrow 2)\end{array}$ & $\begin{array}{l}2(0 \rightarrow 2) ; 6(0 \rightarrow 1) ; 31(1 \rightarrow 2) ; 32(0 \rightarrow 1) ; 34(0 \rightarrow 1) ; 40(0 \rightarrow 1) \\
41(0 \rightarrow 1)\end{array}$ \\
\hline 55 & $31(1 \rightarrow 2) ; 35(0 \rightarrow 1) ; 36(0 \rightarrow 1)$ & $35(0 \rightarrow 1) ; 36(0 \rightarrow 1)$ \\
\hline 56 & $3(1 \rightarrow 2) ; 13(0 \rightarrow 1) ; 17(0 \rightarrow 1) ; 19(0 \rightarrow 1) ; 22(0 \rightarrow 1) ; 24(0 \rightarrow 2) ; 27(0 \rightarrow 1)$ & $\begin{array}{l}\mathbf{3}(\mathbf{1} \rightarrow \mathbf{2}) ; 13(0 \rightarrow 1) ; 17(0 \rightarrow 1) ; 19(0 \rightarrow 1) ; 22(0 \rightarrow 1) ; 24(0 \rightarrow 2) ; \\
27(0 \rightarrow 1)\end{array}$ \\
\hline 57 & $2(1 \rightarrow 0) ; 16(2 \rightarrow 0)$ & $16(2 \rightarrow 0)$ \\
\hline 58 & $1(0 \rightarrow 1) ; \mathbf{1 1}(\mathbf{0} \rightarrow \mathbf{1}) ; 32(1 \rightarrow 0) ; \mathbf{3 7}(\mathbf{1} \rightarrow \mathbf{2}) ; 42(0 \rightarrow 1)$ & $1(0 \rightarrow 1) ; \mathbf{1 1}(\mathbf{0} \rightarrow \mathbf{1}) ; 32(1 \rightarrow 0) ; \mathbf{3 7}(\mathbf{1} \boldsymbol{\rightarrow 2}) ; 42(0 \rightarrow 1)$ \\
\hline 59 & $2(0 \rightarrow 1) ; \mathbf{9}(\mathbf{0} \rightarrow \mathbf{1}) ; 21(0 \rightarrow 1)$ & $8(0 \rightarrow 1) ; \mathbf{9}(\mathbf{0} \rightarrow \mathbf{1}) ; 21(0 \rightarrow 1)$ \\
\hline 60 & $8(0 \rightarrow 1) ; \mathbf{1 6}(\mathbf{1} \rightarrow \mathbf{2}) ; 33(0 \rightarrow 1) ; \mathbf{3 9}(0 \rightarrow \mathbf{1})$ & $16(0 \rightarrow 2) ; 33(0 \rightarrow 1) ; \mathbf{3 9}(\mathbf{0 \rightarrow 1})$ \\
\hline 61 & $\mathbf{3}(\mathbf{1} \rightarrow \mathbf{0}) ; 4(0 \rightarrow 1) ; 12(0 \rightarrow 1) ; \mathbf{2 4}(\mathbf{0} \rightarrow \mathbf{1}) ; 42(0 \rightarrow 1)$ & $\mathbf{3}(\mathbf{1} \rightarrow \mathbf{0}) ; 12(0 \rightarrow 1) ; 16(0 \rightarrow 1) ; \mathbf{2 4}(\mathbf{0} \rightarrow \mathbf{1}) ; 42(0 \rightarrow 1)$ \\
\hline 62 & $16(0 \rightarrow 1)$ & \\
\hline
\end{tabular}

